\title{
During replicative aging, changes in DNA double-strand break repair correlate with an increased rate of mutation.
}

Aditya Mojumdar ${ }^{\dagger}$, Nicola Mair ${ }^{\dagger}$, and Nancy Adam, and Jennifer Cobb*

Departments of Biochemistry \& Molecular Biology and Oncology, Robson DNA Science Centre, Arnie Charbonneau Cancer Institute, Cumming School of Medicine; University of Calgary; 3330 Hospital Drive N.W., Calgary, AB T2N 4N1, Canada.

${ }^{\dagger}$ These authors contributed equally to this work.

* Lead Contact: Tel.: +1 4032208580 or Email: jcobb@ucalgary.ca

\section{Highlights:}

- Decreased DNA resection at DSBs is an early event of replicative aging

- End-joining repair increases as resection decreases at DSBs in older cells

- In older cells the products of DSB repair contain deletions and microhomologies

- DSBs associate with the NPC at the nuclear periphery more in older cells

- Old Cell Enrichment method suitable for molecular biology approaches in budding yeast

Keywords: replicative aging, DSB repair, DNA end resection, homologous recombination (HR), non-homologous end-joining (NHEJ), alt-repair, nuclear localization

\section{Author contributions}

A.M., N.M. and J.A.C. designed the research.

A.M., N.M. and N.A. performed experiments and analyzed the data.

A.M., N.M. and J.A.C wrote the manuscript. 


\section{Acknowledgements}

This work was supported by operating grants from CIHR MOP-82736; MOP-137062 and NSERC 418122 awarded to J.A.C. We acknowledge the resources provided by the Live Cell Imaging Laboratory. The Nikon Ti Eclipse inverted epi-fluorescence microscope system was purchased with funds from the International Microbiome Centre, which is supported by the Cumming School of Medicine at University of Calgary, Western Economic Diversification (WED) and Alberta Economic Development and Trade (AEDT), Canada.

Conflict of Interest: The authors have no real or perceived conflicts of interest financially or otherwise to declare. 


\begin{abstract}
A double -strand break (DSB) is one of the most deleterious forms of DNA damage. In eukaryotic cells, two main repair pathways have evolved to repair DSBs, homologous recombination (HR) and non-homologous end-joining (NHEJ). During replicative aging in the unicellular eukaryotic organism, S. cerevisiae, the relative use of HR and NHEJ shifts in favor of end-joining repair. By monitoring repair events in the HO-DSB system, we show that DNA resection decreased early in replicative aging as did the recovery of long-range resection factors, Dna2-Sgs1 and Exo1. As aging progressed, the retention of Ku70 then decreased and irreparable DSBs accumulated with the pore complex at the nuclear periphery. End-bridging remained intact as HR and NHEJ declined, but eventually it became disrupted in cells of older replicative age. In all, our work provides insight about age-related molecular changes in DSB repair, where both canonical pathways become disrupted. HR declines first, leading to a transient reliance on NHEJ, which then also declines as cells repair through a mechanism yielding products with larger deletions and 1-2bp of microhomologies at break junctions.
\end{abstract}




\section{Introduction}

Age is the greatest risk factor for developing cells with genome instability and most types of cancer (Hoeijmakers 2009). There are strong links between aging and genome instability diseases. For example, the majority of diseases with accelerated/premature aging phenotypes are caused by mutations in DNA repair factors and DNA damage is a driver of aging. The overall accumulation of DNA damage is governed by the relative rate of damage formation balanced with the rate of repair, and both are impacted by age. In older cells, DNA damage formation increases and this correlates with changes in genome organization and compaction (Hu et al. 2014). At the same time however, the rate of DNA repair decreases. Indeed, cells from older individuals show a lower rate of DSB repair compared to cells from younger individuals (Mayer et al. 1989; Singh et al. 1990). These observation have been extremely informative, however it still remains challenging to define the molecular underpinnings that drive age-related increases in genome instability (Niedernhofer et al. 2018).

Genomic rearrangements arise from disruptions during DNA double-strand break (DSB) repair and these types of mutations accumulate with increased age (Gorbunova \& Seluanov 2016). The phosphorylation of histone $\mathrm{H} 2 \mathrm{AX}(\gamma \mathrm{H} 2 \mathrm{AX})$ in humans, which corresponds to $\mathrm{H} 2 \mathrm{~A}(\gamma \mathrm{H} 2 \mathrm{~A})$ in budding yeast, is an indirect measure of DSB formation. The level of $\gamma \mathrm{H} 2 \mathrm{AX}$ increases with age, however a unified model for understanding why this occurs is proving to be complex in part because there are multiple pathways for repairing DSBs. These include two canonical pathways, nonhomologous end joining (NHEJ) and homologous recombination (HR), and multiple alternative pathways that are highly mutagenic and primarily used when the rates of NHEJ and HR decrease (Fig. 1A). HR is considered to be error-free as it uses the sister chromatid as a template and can faithfully repair the DSB without loss of genetic material. By contrast, NHEJ is error-prone and often incorporates small DNA insertions or deletions at the break site. The relative use of these DSB repair pathways is not uniform across eukaryotes, or uniform in different cell types or developmental stages of the same organism, even under optimal conditions. Yeast cells repair DSBs largely by homologous recombination (HR) whereas human cells rely on NHEJ to a greater exist, however HR and NHEJ are functional in both. 
Insights about how DSB repair proceeds during aging have been gained, although working with aging tissue in multicellular organisms remains extremely challenging (Gorbunova \& Seluanov 2016; Niedernhofer et al. 2018). Altered intracellular distribution of Ku70/80 (Ku) and decreased protein levels for Ku and Mre11 have been reported in aging human cells (Um et al. 2003; Ju et al. 2006; Seluanov et al. 2007; Mao et al. 2012). However, changes in protein expression do not necessarily specify which pathway will be used to repair a DSB. Highlighting this case in point, the rate of HR repair decreased in the germline of old flies compared to young flies, yet the expression of HR components increased rather than decreased (Delabaere et al. 2017).

Cell cycle properties and genome maintenance factors are widely conserved in all eukaryotes and budding yeast has proven to be a robust system for identifying many of the steps in DSB repair. Recent work has shown a reduction in the levels of HR proteins in older yeast cells as well as a reduction in the use of single-strand annealing (SSA), an alternative repair pathway relying on DNA resection at the break and sequence homology (Pal et al. 2018; Young et al. 2019). However, beyond this there is surprisingly little known about the integrity of DSB repair mechanisms over the replicative lifespan of yeast. Much of the seminal work for monitoring physical events in DSB repair have used the galactose-inducible $\mathrm{HO}$ endonuclease system, which creates one site-specific DSB synchronously in the yeast genome (Connolly et al. 1988). Here, we use this well-characterized system to evaluate key steps in DSB repair in different stages of replicative aging. We measured the recruitment of $\mathrm{HR}$ and NHEJ repair factors to the DSB, determined where irreparable DSBs accumulate at the nuclear periphery, and assessed repair outcomes by sequencing the break junction. Similar to the initial discoveries using the HO system (Jasin \& Haber 2016), we believe that characterizing DSB repair in relationship to lifespan be relevant for understanding the connection between aging and genome maintenance in higher eukaryotes, and by extension cancer initiation in human cells. 


\section{Results}

\section{Old cell enrichment and DSB repair pathway choice}

Due to difficulties in obtaining old yeast cells, knowledge about age-related changes in DSB repair is only starting to emerge (Janssens \& Veenhoff 2016; He et al. 2018; Pal et al. 2018; Young et al. 2019). We have optimized an old cell enrichment (OCE) approach and perform this with cells containing the HO-DSB where one site-specific DSB can be created by galactoseinduction of the HO endonuclease (Connolly et al. 1988; Sinclair 2013). This enhanced OCE method transformed our ability to rapidly collect a large number of progressively older cells without the need for specialized microfluidics or a specific genetic background in the Mother Enrichment Program (Lindstrom \& Gottschling 2009). Our method involved biotin cell labelling but differed from previous approaches by the technology used to enrich for old cells. Biotin labelled cells bind to ferromagnetic charged microbeads in the XS column (Miltenyi), which amplifies the magnetic field 10,000-fold in combination with the SuperMACS ${ }^{\mathrm{TM}}$ II separator system (Supplemental Fig. S1A). Young cells pass through the column and old cells are retained. After washing to remove young cell contaminants, old cells can be eluted from the XS column by withdrawing the magnetic field.

We sorted young $(\mathrm{Y})$ from progressively older $(\mathrm{O})$ cells at the following times $18 \mathrm{hrs}(\mathrm{O} 1), 42 \mathrm{hrs}$ (O2) and $66 \mathrm{hrs}(\mathrm{O} 3)$ after the initial biotin labelling. The $\mathrm{Y}$ cells were the daughters from the first night of old cell enrichment that did not bind to the XS column when cells aged to 01 were recovered. 01 cells were either used for experiments or re-inoculated in fresh media and grown $24 \mathrm{hrs}$ more (O2 cells). The same process was repeated with $\mathrm{O} 2$-aged cells to yield $\mathrm{O} 3$ cells (Supplemental Fig. S1A). Haploid yeast goes through an average of $\sim 25$ divisions during their lifespan (Mortimer \& Johnston 1959). The number of cellular divisions was determined by counting the number of bud scars on the surface of the mother cell visualized by calcofluor white, which labels chitin enriched around the bud site (Fig. 1B, C; Supplemental Fig. S1B) (Vrsanská et al. 1979). Cells in the oldest culture, O3, averaged 17 bud scars (Fig. 1B, C). The level of Sir 2 histone deacetylase decreases with age and its target is histone H4K16. Older cells obtained from this OCE method showed increased H4K16 acetylation, thus beside bud scar 
count, we verified that old cells displayed other known markers of replicative aging (Supplemental Fig. S1C).

Two important events at a DSB that we first assessed were DNA resection and DNA endbridging (Fig. 1A). Resection is necessary for HR but prevents the possibility of NHEJ. DNA endbridging holds the broken ends in close proximity and provides structural support during end processing. To determine resection at the HO-DSB we used a quantitative PCR-based approach after galactose induction of the HO endonuclease. Genomic DNA was prepared at the indicated timepoints and digested with the Rsal restriction enzyme followed by quantitative PCR. This method relies on a $R$ sal cut site located $0.15 \mathrm{~Kb}$ from the DSB (Fig. 1D). If resection progresses past the Rsal recognition site, then the single-stranded DNA generated from resection would not be cleaved by Rsal, and would amplify by PCR (Ferrari et al. 2015; Mojumdar et al. 2019; Mojumdar et al. 2022b; Hohl et al. 2020). Resection in Y cells proceed similarly to overnight cultures not passed over the XS column (Supplemental Fig. S1D). We were encouraged that there were no off-target effects to resection arising from OCE. In contrast to $Y$ cells, resection in 01-O3 aged cells progressively decreased as cellular age increased (Fig. 1E). In $\mathrm{O} 2$ and $\mathrm{O} 3$ samples, this might be partly due to a decrease in $\mathrm{HO}$ cutting that was most pronounced 40 minutes after induction (Supplemental Fig. S1E). O1 cells averaging $\sim 6$ divisions showed a marked decrease in resection but had > 75\% lifespan remaining (Mortimer \& Johnston 1959). Cell-cycle analysis by flow cytometry was also performed on cells after OCE and prior to galactose induction. Y cells had $\sim 9 \%$ fewer cells in G1 compared to 01 (Supplemental Fig. S1F), a minor difference that likely cannot account for the 2-3-fold decrease in resection (Fig. 1E). End bridging was measured in cells where both sides of the DSB were tagged with fluorescent markers. The TetO array and the LacO array were integrated $3.2 \mathrm{~Kb}$ upstream and $5.2 \mathrm{~Kb}$ downstream respectively from the DSB in cells expressing TetR ${ }^{\text {GFP }}$ and LacO ${ }^{m C h e r r y}$ fusions, enabling us to visualize both sides of the break by fluorescence microscopy (Fig. 1F). 2 hours after HO-induction the distance between the GFP and mCherry foci was similar for $\mathrm{Y}$ and O1aged cells at $0.30 \mu \mathrm{m}$ and $0.27 \mu \mathrm{m}$ respectively and increased slightly in 02 cells $(0.39 \mu \mathrm{m})$. In 03-aged cells there was a significant increase in the mean distance $(0.58 \mu \mathrm{m})$ and wide distribution of inter-foci that likely reflected $\mathrm{HO}$ cutting defects at the population level, as foci 
in uncut cells would be very close (Fig. 1F). In all, early in the cell's replicative age, end-bridging was intact, but DNA resection decreased. HR is the main DSB repair pathway in yeast, however, most, if not all, studies investigating pathway choice have been performed with cultures containing mostly young cells. Thus, one possibility is that the preference for HR repair is a young yeast cell phenomenon that declines with age. To explore this, we were prompted to investigate the recruitment levels of repair factors that drive resection.

\section{Reduced recruitment of resection factors during aging.}

Mre11-Rad50-Xrs2 (MRX) and yKu70/80 (Ku) are the first complexes recruited to a DSB (Fig. 2A) (Wu et al. 2008). DNA resection occurs through a two-step process (Ciccia \& Symington 2016). In the first step, Sae2, the yeast homologue of human CtIP, activates Mre11 endonuclease to cleave 100bp away from the DSB and initiate 3'-5 DNA resection towards the break. This causes Ku to dissociate, and when that happens, NHEJ is prevented. In the second step of resection, two functionally redundant $5^{\prime}$ to $3^{\prime}$ nucleases, Dna2 in complex with Sgs1 and Exo1, catalyze long-range resection (Zhu et al. 2008; Cejka 2015). The physical presence of the MRX complex is critical for all resection because both long-range nucleases require MRX for their localization. (Mimitou \& Symington 2008; Zhu et al. 2008).

We performed chromatin immuno-precipitation (ChIP) on Mre11 and Rad50, two members of the MRX complex, with primers located $0.6 \mathrm{~kb}$ from the DSB (Fig. 2B-C). The recovery of both increased significantly in $\mathrm{O} 1$ and $\mathrm{O} 2$ cells, with a 2-fold increase seen with Mre11 and a 2 to 4fold increase with Rad50. Unfortunately, ChIP with O3 was precluded due to inefficient HOcutting (Supplemental Fig. S1E) and significantly reduced survival under DSB (Supplemental Fig. S1G). The increased recovery of Mre11 and Rad50 was surprising as previous work showed that older cells have a decreased level of HR proteins (Pal et al. 2018). Consistent with Pal et al., we also observed a decrease in the overall expression of HR proteins, including MRX components (Supplemental Fig. S2A). Changes in expression levels have been used as readouts for a cell's proficiency in a particular repair pathway (Mao et al. 2012, p.201; Titus et al. 2013; Delabaere et al. 2017). However, these results show that there is not necessarily a direct correlation between protein levels and their recruitment levels. 
In contrast to MRX, the recruitment of Sae2 was reduced in $\mathrm{O} 1$ cells (Fig. 2D), as was the recruitment of the long-range resection components, Dna2-Sgs1 and Exo1 (Fig. 2E-G). Taken together, 01 cell cultures, which have undergone $\sim 6$ cellular divisions show decreased resection and decreased recruitment of key factors driving DNA resection, although MRX showed increased retention. Our observations underscore the value of performing molecular and biochemical work in old cells as we gained information about age-related mechanistic changes in DSB repair. We did not perform ChIP with these factors aged to the $\mathrm{O} 2$ stage as we found it unlikely that their recruitment, which decreased in 01 , would increase in older cells with an even greater resection defect.

\section{Increase in error-prone DSB repair with aging}

We were curious about how DSB repair proceeded when resection, which is the main event driving HR, decline so early in the aging process. Thus, we were next prompted to investigate the usage of NHEJ as end-joining reactions are supported structurally by DNA end-bridging (Mojumdar et al. 2019; Hohl et al. 2015), which remained intact from $Y$ to O2-aged cells. As mentioned, $\mathrm{Ku}$ is one of the first responders to a DSB and it plays a key role in recruiting the other NHEJ factors such as Nej1 and Lif1-Dnl4 (Zahid et al. 2021). We measured the recruitment levels of the core NHEJ factors by ChIP. All the factors showed a similar level of recruitment to the DSB in $\mathrm{Y}$ and $\mathrm{O} 1$ cells, except for Ku70, which was recovered at an increased level in $\mathrm{O} 1$ cells (Figure 3A-B and Supplemental Fig. S3A).

We next determined the level of end-ligation in old cells. For this, a DSB was induced by galactose for 3 hours, then cells were washed and released into glucose to prevent further recutting (Fig. 3C). At the indicated time-points, genomic DNA was prepared followed by qPCR using primers flanking the break site. Amplification across the DSB after release into glucose occur if the broken DNA ends are joined (Mojumdar et al. 2022a). Ligation in 01-aged cells increased 2-fold above $Y$ cells and correlated with the increased recovery of Ku70 (Fig. 3A, D). This increase in end-joining was dependent on NHEJ as deletion of $K U 7 O$ in $O 1$ cells resulted in a complete abrogation of end-joining (Fig. 3D). In O2-aged cells, averaging 11 divisions, there was also a significant reduction in the rate of end-joining. This decrease correlated with a 
marked decrease in Ku70 retention, which was striking given its recovery level at the DSB in 01 aged cells (Fig.3A, D). By contrast, Nej1 at DSBs was not statistically different between $\mathrm{Y}$ to $\mathrm{O} 2$ aged cells (Fig. 3B). It was noticeable that the recovery of Nej1 and MRX did not decrease as replicative age increased from $\mathrm{Y}$ to $\mathrm{O} 2$ cells, and is consistent with both factors functioning independently to maintain end-bridging, which remained intact at these ages (Hohl et al. 2015; Mojumdar et al. 2019).

These relative changes in resection and end-ligation at DSBs highlight the fluid nature of repair pathway choice early during aging. In $\mathrm{O} 1$ cells, resection decreased (Fig. 1F) and end-joining increased suggesting that age-related declines in HR can be absorbed by an almost equivalent rise in NHEJ. In Y cells, when core NHEJ factors were deleted, resection increased (Supplemental Fig. S3C). However, in $\mathrm{O} 1$ cells, preventing NHEJ with $d n / 4 \Delta$, did not increase resection in the way deletions of KU7O or NEJ1 did (Fig. 3E), which highlights their additional roles in inhibiting Exo1 and Dna2 respectively (Mimitou \& Symington 2010; Mojumdar et al. 2019; Mojumdar et al. 2022b; Mojumdar et al. 2022a). It is noteworthy how increased resection by deleting NHEJ factors wanes in older cells, suggesting that genotype-phenotype readouts can not only change with age but that age, as a factor, can be more penetrant than genetic manipulations.

\section{During aging imprecise DSB repair increases the mutational burden on cells.}

Recent work in mammals, flies, and yeast have shown that difficult to repair DNA damage relocates to specific 'repair sites' at the nuclear periphery (Nagai et al. 2008; Chiolo et al. 2011; Chung \& Zhao 2015; Ryu et al. 2015; Su et al. 2015; Churikov et al. 2016; Horigome et al. 2016). Previous work showed that DSBs relocate to the periphery within 1 hour of HO-cutting and can be detected for up to 4 hours after induction. In WT cells after galactose induction, the level of DSBs increase in outer most zone 1 (Fig. 4A) (Nagai et al. 2008; Horigome et al. 2014; Horigome et al. 2016).

Given there were age-related changes in repair pathway usage, we next investigated whether there were changes in DSB localization to the periphery. To do this, we performed highresolution microscopy and monitored the repositioning of the HO-DSB after induction of the HO 
endonuclease. The DSB was visualized by expression of Lacl ${ }^{\text {GFP }}$ in cells where an array lacO sites were integrated $4.4 \mathrm{~kb}$ from the $\mathrm{HO}$ site at the MAT locus. A focal stack of images through a field of cells allowed us to determine the position of the DSB relative to the nuclear periphery, visualized by Nup49 CFP. Nuclear positioning of the DSB was determined in Y and O1 after OCE. $\mathrm{O} 1$ cells showed altered nuclear morphology as visualized by Nup49 ${ }^{\mathrm{CFP}}$ in 2D and 3D reconstructed images (cyan; Fig. 4B). This prevented quantitative zoning analysis, which relied on three concentric circles representing equal areas within the nucleus. However, the overlap of GFP-CFP signals indicated that $52 \%$ of DSBs in Y cells and $50 \%$ of DSBs in 01 cells touched the nuclear periphery (Fig. 4C), and above the 33\% level if the distribution was random or if localization was defective. These results demonstrate that 2 hours after HO induction that, irreparable DSBs in 01-aged cells, become enriched at repair centers located at the nuclear envelope similarly to $\mathrm{Y}$ cells.

In yeast, the nuclear periphery has two independent where yeast damage accumulates, these are the nuclear pore complex (NPC) and the SUN domain protein, Mps3 (Kalocsay et al. 2009; Oza et al. 2009). These sites have different requirements for damage localization and lead to different repair outcomes. DNA intermediates with extensive resection at DSBs are targeted to Mps3, a protective environment that promotes canonical $\mathrm{HR}$ and reduces promiscuous recombination events in S/G2. By contrast, DSBs without extensive resection become enriched at the NPC in all cell cycle phases (Fig. 4D). The nuclear pore is associated with NHEJ and noncanonical alternative repair pathways (Khadaroo et al. 2009). ChIP with NPC components and Mps3 have verified microscopy-based methods and can also quantitatively distinguish between these two specific locations at the periphery. We followed up with ChIP in O2-aged cells because we felt microscopy-based approaches posed a challenge given the age-related morphological changes with nuclear envelope, and because ChIP had worked well for measuring the recruitment of repair factors to DSBs in $\mathrm{Y}$ to $\mathrm{O} 2$ cells (Fig. 2B-G, 3A, B) We performed ChIP with Nup133 ${ }^{\mathrm{Myc}}$, a component of the NPC, and Mps3 ${ }^{\mathrm{HA}}$. Consistent with previous work in Y cells, the break associated robustly with Mps3 and to a lower level with the NPC after galactose induction (Fig. 4E-F; Horigome et al. 2014). The DSB association with Mps3 significantly declined in $\mathrm{O} 1$ and $\mathrm{O} 2$ cells, and in $\mathrm{O} 2$-aged cells it was at non-induced, background 
levels (Fig. 4E). By contrast, the association of the DSB with the NPC showed a progressive 2fold and 3-fold increase in $\mathrm{O} 1$ and $\mathrm{O} 2$ aged cells respectively (Fig 4F).

As mentioned, the NPC is associated with NHEJ and other more mutagenic alt-repair pathways (Nagai et al. 2008; Khadaroo et al. 2009; Su et al. 2015; Horigome et al. 2016; Therizols et al. 2006). To determine if age-related changes in end-joining and nuclear periphery location reflected a physiological change in how DNA was being processed at the DSB, we sequenced across break junction of young and old cell survivors. Survivors arise during continuous HO endonuclease induction when repair is mutagenic, and the HO site is not recognized for recleavage. Consistent with previous work, the most common mutations seen in $\mathrm{Y}$ and $\mathrm{O} 1$ survivors were a 2-bp (+CA) insertion and a 3-bp (-ACA) deletion and other 1-3 bp indels produced from canonical NHEJ (Table 1) (Moore \& Haber 1996; Mojumdar et al. 2019). By contrast, mutations in $\mathrm{O} 2$ survivors were primarily 4-6 bp deletions with 1-2 bp of microhomology (MH) (Table 1) (Ma et al. 2003). Taken together, these data are consistent with a model whereby older cells use an end-joining mechanism to repair DSBs that correlated with decreased Ku and increased NPC association, a pathway infrequently used in young cells. 


\section{Discussion}

Here we report age-dependent mechanistic changes in DSB repair in the unicellular eukaryotic organism S. cerevisiae. Early in replicative aging resection decreased and the recruitment of HR factors decreased. As HR declined there was a shift towards the usage of end-joining mechanisms and a progressive increase in the frequency of repair products with larger deletions and $\mathrm{MHs}$ at break junctions. For this work to be possible we develop an old cell enrichment method that purified enough old cells at various stages of aging for molecular and biochemical studies.

\section{Old cell enrichment}

The old cell enrichment method we developed was an adapted method involving biotin labelling (Sinclair 2013), and was possible because of advanced biotin binding technology that was commercially available (Supplemental Fig. S1A). Our approach was surprisingly uncomplicated, allowing large quantities of biotin labeled mother cells to be isolated with minimal young cell contamination. Many yeast aging studies have combined biotin labelling with the 'Mother enrichment program' (MEP), which is based on a Cre-Lox system that needs to be integrated into the yeast genome (Lindstrom \& Gottschling 2009). Our approach was not combined with the MEP and did not require estradiol treatment to kill off daughter cells, but rather permitted their recovery, which might be valuable for future large-scale studies comparing daughter cells from young and old mothers.

Our work was performed in cell populations of increased age where replicative age was determined by bud scar count on individual cells in $\mathrm{Y}$ to O3-aged cultures (Fig. 1B, C). When comparing between samples, there was overlap in the number of cellular divisions. However, all cells in the $\mathrm{O} 2$ population were at a replicative age older than $\mathrm{Y}$ cells. DSB formation in $\mathrm{Y}$ to $\mathrm{O} 3$ aged cells showed reduced efficiency upon galactose induction. While 01 aged cells were indistinguishable from $Y$ cells with $>99 \%$ HO cutting, 02 aged cells showed $\sim 18 \%$ reduction (Supplemental Tables S1 and S2). However, the recovery of key factors like Mre11 and Nej1 were similar in ChIP experiments between $\mathrm{Y}$ and O2, therefore we considered the reduced cutting to be of relatively minor impact for our overall interpretations. ChIPs in O3-aged cells 
were not attempted for several reasons including the further reduction in HO cutting efficiency, and more notably because DNA processing events like resection and ligation were largely undetected. Importantly, overall survival in $\mathrm{O} 3$ cells significantly decreased and coincided with the loss of end-bridging. Future work during this late stage of replicative aging would be a worthy pursuit as sequencing survivors could reveal another category of mutations that develop when end-bridging becomes disrupted. However, this would require a scale-up in the quantity of cells enriched to $\mathrm{O} 3$ as survival is $<0.02 \%$ with continuous induction (Supplemental Fig. S1G) in $\mathrm{O} 3$ aged cells, which was a 10 -fold lower survival rate in $\mathrm{Y}$ to $\mathrm{O} 2$-aged cells.

\section{Age-related changes in repair pathway usage}

Our work catalogues molecular changes in DSB repair in yeast cells at different stages of replicative lifespan and provides insight about how mechanisms that preserve genome maintenance in eukaryotic cells evolve with age. While the relative use and efficiency of repair pathways is known to be impacted by cell type, cell cycle phase, and ploidy, very little is known about how cellular age impacts the molecular events driving DSB repair pathway choice (Kadyk \& Hartwell 1992; Trovesi et al. 2011).

DSBs are dangerous lesions and when not properly repaired they can lead to an increased mutational burden or cell death. We have measured age-dependent mechanistic changes in DSB repair and see that cellular age emphasizes these unfortunate repair outcomes.

In yeast, the relative use of the two canonical DSB pathways, HR and NHEJ, is 10 to 1 in favor of HR (Valencia-Burton et al. 2006). Our data suggest that this ratio is specific to very 'young' yeast cells. We find that early in the cell's replicative lifespan, by 6 divisions in 01 aged, that the frequency of resection, which is the first step in HR, decreases (Fig. 1E). At this same stage in replicative aging, the frequency of end-joining increases, and serves as a back-up when HR declines rather than being in competition with HR (Fig. 3D, E). Deletion of DNL4 in O1 cells did not restore resection at the HO-DSB (Fig. 3E), indicating that there are intrinsic age-related decreases in HR efficiency, independent of NHEJ usage, that decline with age. These results align well with previous work which showed that single-strand annealing (SSA), an alternative DSB repair pathway dependent on resection, declined with increased replicative age and was 
not restored by $d n / 4 \Delta$ (Young et al. 2019). Decreased resection likely stemmed from a reduction in HR factors as their overexpression restored DSB repair in older cells following MMS treatment and extended lifespan (Pal et al. 2018). First shown by others, and reproduced here by us, the expression of HR protein decrease with age (Supplemental Fig. S2) (Pal et al. 2018). We show here that in addition to reduced protein levels, that there are significant decreases in the recruitment of specific HR factors to the DSB (Fig. 2). The largest relative decrease we observed between $\mathrm{Y}$ and $\mathrm{O} 1$ cells was the 3-fold decrease in Dna2 recruitment to the DSB, which correlated with decreased expression (Fig. 2E and Supplemental Fig. S2A).

Our work also showed that changes in the stoichiometry of repair proteins at DSBs impacted repair pathway choice and corresponded with the shift from HR to end-joining early in replicative aging. HR was compromised relatively early in lifespan and in response, end-joining increased. Consistent with this, there was a significant increase in the retention of Ku at DSBs in 01-aged cells, as well as Mre11 and Rad50 even though protein levels decreased (Fig. 2C, 3A, and Supplemental Fig. S2A, B). Furthermore, when the recovery of most HR factors involved in resection decreased, the core NHEJ factors remained constant, including Nej1 and Lif1-DnI4. With increased age, in 02-aged cells, both resection and end-joining decreased, and this correlated with a marked decrease in $\mathrm{Ku}$ (Fig. 3A), however the level of other end-joining factors, such as Nej1, remained constant (Fig. 3B).

\section{End-joining repair in progressively older cells}

From sequencing the break point junction of survivors, repair events during continuous HO induction shifted from 1-3 bp indel events when the break was induced in Y cells to larger deletions with 1-2 bp MHs at the junction when the break was induced in O2 cells (Table 1) (Ma et al. 2003). It is thought provoking as to whether repair products in $\mathrm{O} 2$ cells result from NHEJ or whether these repair events can be categorized as microhomology end-joining (MMEJ). NHEJ products can have $\mathrm{MH}$ and one litmus test for $\mathrm{MMEJ}$ is whether the end-joining event occurs in the absence of $\mathrm{Ku}$. MMEJ products in yeast normally have 4-6 bp MHs and occur the absence of $\mathrm{Ku}$, when the thermodynamics of NHEJ are not favored. However, most MMEJ work has been 
performed in young cells with reporter systems where $\mathrm{MH}$ length and location relative to the break can be regulated (McVey \& Lee 2008; Sinha et al. 2016; Pannunzio et al. 2014). Naturally occurring MMEJ in cells late in their replicative lifespan has never been reported. In $\mathrm{O} 2$ aged cells which is $\sim 44 \%$ of lifespan, Ku70 recovery at the DSB was reduced to background levels (Fig. 3A). Thus, the local environment might indeed be a site where end-joining is coordinated, independently of Ku. Alternatively, Ku70 might be present below the level of detection. Either way, the repair products in $\mathrm{O} 2$ are rarely seen in young cells with the same genotype.

It is noteworthy that factors identified through the use of reporter systems to be critical for MMEJ, such as MRX and Nej1, were present at the DSB in O2 cells (McVey \& Lee 2008; Sinha et al. 2016). In yeast, MRX is uniquely integral to most repair mechanisms, including $H R$ and both NHEJ and MMEJ. MRX may help regulate repair pathway usage is by controlling the extent of resection at the break. While HR requires extensive resection, MMEJ requires minimal resection. The $3^{\prime}-5^{\prime}$ exonuclease activity of MRX is important to initiate resection as it removes nucleotides at the DSB in 100 bp increments in a 3' to 5' direction (McVey \& Lee 2008; Sinha et al. 2016). If Ku dissociates, then NHEJ cannot occur and if resection is reduced, then HR will not proceed. However, if other end-joining factors are present like Nej1 and Lif1-Dnl4 or Cdc9 ligase, then the break can be sealed through MMEJ, but with larger deletions. This represents the culmination of events in $\mathrm{O} 2$-aged cells.

\section{Changes in morphology and locations at the periphery}

Work performed in human and yeast have linked nuclear architecture with aging and genome stability pathways (Lans \& Hoeijmakers 2006; Kubben \& Misteli 2017). Naturally aged yeast showed an increase in nuclear envelope herniations associated with NPC regions and a decline in NPC assembly (Janssens \& Veenhoff 2016; Rempel et al. 2020). The stability of the genome relies on the sequestration and compartmentalizing of irreparable DSBs at the nuclear periphery in environments conducive to repair. In humans, breaks at the nuclear lamina are repaired through MMEJ. In yeast, the NPC is the location where end-joining repair occurs, both NHEJ and MMEJ. In $\mathrm{O} 2$ aged cells there was a 3-fold increase in DBSs associated with the NPC 
(Fig. 4F). Indeed, disruptions in nuclear pore components results in reduced survival after DNA damage exposure (Nagai et al. 2008; Loeillet et al. 2005) and single cells that maintain NPC components live longer. Thus, declined NPC function in older cells might not only impact shuttling in and out of the nucleus, but it might also impact the efficiency of DSB repair, which accumulate at nuclear pores more in older cells (Fig 4E-F). The NPC compart at the nuclear periphery might be integral to understanding the relationship between aging and genome stability, and it will be interesting to assess whether deterioration of the NPC in older cells is related to an accelerated mutation rate at the $\mathrm{HO}$ site.

A significant number of pathways controlling yeast replicative aging appear to be fundamentally conserved and impact aging in higher eukaryotes like humans, including pathways important in genome stability and chromatin organization. Significant aging research performed in yeast has focused on the rDNA repeat region (Ganley \& Kobayashi 2014). The accumulation of extrachromosomal rDNA circles (ERCs), produced by recombination within the repeat region, are retained in old cells through a mechanism involving their localization to the NPC (Denoth Lippuner et al. 2014). Given this is the site where we see irreparable DSBs targeted for repair in aging cells; our observations may be related to the reasons why rDNA instability and ERC formation impact global genome stability in old cells (Pal et al. 2018; Ganley \& Kobayashi 2014). Increased ERCs at nuclear pores could impact the efficiency of end-joining repair in old cells, resulting in the increased rates of genomic $\gamma \mathrm{H} 2 \mathrm{AX}$ and translocations in old cells (Hu et al. 2014). 


\section{MATERIALS AND METHODS}

KEY RESOURCE TABLE

\begin{tabular}{|c|c|c|}
\hline REAGENT or RESOURCE & SOURCE & IDENTIFIER \\
\hline \multicolumn{3}{|l|}{ Antibodies } \\
\hline HA-probe mouse monoclonal antibody & Santa Cruz Biotechnology & $\mathrm{F}-7$ \\
\hline FLAG-Probe mouse monoclonal antibody & Santa Cruz Biotechnology & M2F12 \\
\hline Myc-Probe mouse monoclonal antibody & Abcam & ab32 \\
\hline Peroxidase conjugated AffiniPure Goat anti-Mouse antibody & Jackson ImmunoResearch & 115035174 \\
\hline \multicolumn{3}{|l|}{ Chemicals } \\
\hline$\alpha-$ factor & EZBiolab & CP7206 \\
\hline Adenine & Sigma & A8626 \\
\hline Albumin, Bovine Serum, Fraction $V$, low heavy metals & Calbiochem & 12659 \\
\hline Ammonium sulfate & VWR & BDH9216 \\
\hline Anti-Biotin MicroBeads & Miltenyi Biotec & $130-090-485$ \\
\hline Bacto $^{\mathrm{TM}}$ Peptone & BD Biosciences & 211677 \\
\hline Bacto $^{\text {TM }}$ Yeast extract & BD Biosciences & 212750 \\
\hline Calcofluor white stain & Sigma & 18909 \\
\hline Complete EDTA free protease inhibitor cocktail & Roche & 04693159001 \\
\hline Dextrose & Sigma & D1912 \\
\hline Difco $^{\mathrm{TM}}$ Agar & BD Biosciences & 214530 \\
\hline $\begin{array}{l}\text { Difco }{ }^{\mathrm{TM}} \text { Yeast Nitrogen Base wo Amino Acids and } \\
\text { Ammonium Sulfate }\end{array}$ & BD Biosciences & 233520 \\
\hline Dynabeads Sheep anti-Mouse IgG & Invitrogen & 20230531 \\
\hline EDTA & VWR & 0322 \\
\hline Ethanol & Commercial alcohols & P006EAAN \\
\hline $\begin{array}{l}\text { Ez-Link }^{\mathrm{TM}} \text { Sulfo-NHS-LC-Biotin Sulfosuccinimidyl-6- } \\
\text { (biotinamido) hexanoate }\end{array}$ & Thermoscientific & 21335 \\
\hline Formaldehyde & Sigma & F8775 \\
\hline Galactose & Sigma & G0750 \\
\hline Glycine & VWR & CA93291 \\
\hline Glycogen & Roche & 10901393001 \\
\hline L-Arginine monohydrochloride & Sigma & A5131 \\
\hline L-Aspartic Acid & Sigma & A9256 \\
\hline L-Glutamic Acid & Sigma & G1626 \\
\hline L-Histidine & Sigma & $\mathrm{H} 8000$ \\
\hline L-Isoleucine & Sigma & 12752 \\
\hline L-leucine & Sigma & L8000 \\
\hline L-Lysine & Sigma & L5501 \\
\hline L-Methionine & Sigma & M9625 \\
\hline L-Phenylalanine & Sigma & P2126 \\
\hline L-Serine & Sigma & S4500 \\
\hline L-Threonine & Sigma & T8625 \\
\hline L-Tryptophan & Sigma & T0254 \\
\hline L-Tyrosine & Sigma & T3754 \\
\hline
\end{tabular}




\begin{tabular}{|c|c|c|}
\hline L-Valine & Sigma & V0500 \\
\hline Lactic acid & Sigma & 69785 \\
\hline Lithium Chloride & EMD Millipore & LX03311 \\
\hline Paraformaldehyde & Sigma & 158127 \\
\hline Phenol-Chloroform-Isoamylalcohol & Invitrogen & 15593049 \\
\hline PMSF & Sigma & 78830 \\
\hline Potassium Chloride & EMD Chemicals & 1049360500 \\
\hline Potassium phosphate monobasic & Sigma & P9791 \\
\hline Raffinose & US Biological & R1030 \\
\hline SDS & Avantor & 409502 \\
\hline Sodium Acetate & VWR & BDH9278 \\
\hline Sodium Chloride & Fisher Chemical & S64212 \\
\hline Sodium hydroxide & EMD Millipore & $1310-73-2$ \\
\hline Sodium phosphate, dibasic, anhydrous & VWR & $84486-300$ \\
\hline SuperMACS ${ }^{\mathrm{TM}}$ II Separator & Miltenyi Biotec & $130-044-104$ \\
\hline Tris base & Fisher Chemical & BP1525 \\
\hline Triton & Sigma & 9002931 \\
\hline Uracil Minimum 99\% & Sigma & U0750 \\
\hline XS Columns & Miltenyi Biotec & 130-041-202 \\
\hline Zirconia Silica beads & BioSpec Products & $11079105 z$ \\
\hline \multicolumn{3}{|l|}{ Enzymes } \\
\hline Proteinase $\mathrm{K}$ & Invitrogen & 25530031 \\
\hline RNase A & Sigma & R6513 \\
\hline Rsal & New England Biolabs & R0167S \\
\hline \multicolumn{3}{|l|}{ Kits } \\
\hline PerfeCTa qPCR SuperMix, ROX & Quanta BioSciences Inc. & $89168-786$ \\
\hline PowerUp SYBR Green Master Mix & Applied Biosystems & A25743 \\
\hline Western Lightning Plus-ECL & PerkinElmer & NEL105001EA \\
\hline \multicolumn{3}{|l|}{ Primers } \\
\hline Primers used in this study & Table S4 & \\
\hline \multicolumn{3}{|l|}{ Yeast strains } \\
\hline Yeast strains used in this study & Table S3 & \\
\hline
\end{tabular}

\section{METHOD DETAILS}

\section{Old Cell Enrichment}

Old cell enrichment (OCE) was based on (Sinclair 2013). For all assays $20 \mathrm{ml}$ of overnight culture was inoculated in YPAD medium at 25 degrees. Cells were there diluted to a volume of $100 \mathrm{ml}$ of YPAD and grown into log phase. Cells were harvested and washed three timed with $1 x$ phosphate buffered saline (PBS). Cells were then resuspended in $1 \mathrm{ml}$ PBS and mixed with $8 \mathrm{mg}$ of Sulfo-NHSLC- Biotin per $1 \times 10^{8}$ cells for 30 min at $30^{\circ} \mathrm{C}$. Cells were washed three times with $1 \mathrm{ml} P B S$ and $0.1 \mathrm{M}$ Glycine and used to inoculate $500 \mathrm{ml} \mathrm{SC}$ media overnight at $25^{\circ} \mathrm{C}$. Cells were then harvested 
at 5000rpm for 10 minutes and washed three times with PBS. Cells were then incubated in 50ml PBS and $20 \mu \mathrm{l}$ of Anti-Biotin Microbeads per $10^{7}$ total cells at $4^{\circ} \mathrm{C}$ for 30 mins. Young and old cells were then separated using a XS column on the SuperMACS II separator and washed thoroughly with PBS.

\section{Bud Scar Microscopy}

Following old cell enrichment $20 \mu \mathrm{l}$ of cells were collected and fixed with $2 \mu \mathrm{l}$ of formaldehyde. Cells were then pelleted and stored in 4 degrees for imaging. Cells are resuspended in $20 \mu$ of PBS and stained with calcofluor. Cells are then placed on coverslips and imaged using Zeiss LSM 880 with Airyscan. Z-stack images were acquired with $0.35 \mu \mathrm{m}$ along the $z$ plane using a planapochromat 63x/1.40 Oil Dic M27 objective. Images were analysed used ZenBlue software. Each cell was analysed individually and $>50$ cells were analysed per sample.

\section{Chromatin Immunoprecipitation}

ChIP assay was performed as described previously (Mojumdar et al. 2019). Cells were collected from the OCE process and resuspended in $200 \mathrm{ml}$ YPLG at $30^{\circ} \mathrm{C}$. $2 \%$ GAL was added to the YPLG and cells were harvested and crosslinked at various time points using $3.7 \%$ formaldehyde solution. Following crosslinking, the cells were washed with ice cold PBS and the pellet stored at $-80^{\circ} \mathrm{C}$. The pellet was re-suspended in lysis buffer (50mM Hepes pH 7.5, $1 \mathrm{mM}$ EDTA, $80 \mathrm{mM} \mathrm{NaCl}$, 1\% Triton, 1mM PMSF and protease inhibitor cocktail) and cells were lysed using Zirconia beads and a bead beater. Chromatin fractionation was performed to enhance the chromatin bound nuclear fraction by spinning the cell lysate at 13,200rpm for 15 minutes and discarding the supernatant. The pellet was re-suspended in lysis buffer and sonicated to yield DNA fragments ( 500 bps in length). The sonicated lysate was then incubated in beads + anti-HA/Myc Antibody or unconjugated beads (control) for $2 \mathrm{hrs}$ at $4^{\circ} \mathrm{C}$. The beads were washed using wash buffer (100mM Tris pH 8, 250mM LiCl, 150mM (HA Ab) or 500mM (Myc Ab) NaCl, 0.5\% NP-40, 1mM EDTA, 1mM PMSF and protease inhibitor cocktail) and protein-DNA complex was eluted by reverse crosslinking using 1\%SDS in TE buffer, followed by proteinase $\mathrm{K}$ treatment and DNA isolation via phenol-chloroform-isoamyl alcohol extraction. Quantitative PCR was performed using the Applied Biosystem QuantStudio 6 Flex machine. PerfeCTa qPCR SuperMix, ROX was used to visualize enrichment at $\mathrm{HO} 2$ (0.5kb from DSB) and HO1 (1.6kb from DSB) and SMC2 was used as an internal control.

\section{qPCR based Resection Assay}

Cells from each strain were collected from the OCE process and resuspended in $15 \mathrm{ml} \mathrm{YPLG}$. 2.5mL of the cells were pelleted as timepoint 0 sample, and $2 \%$ GAL was added to the remaining cells, to induce a DSB. Following that, respective timepoint samples were collected. Genomic DNA was purified using standard genomic preparation method by isopropanol precipitation and ethanol 
washing, and DNA was re-suspended in $100 \mathrm{~mL} d \mathrm{dH}_{2} \mathrm{O}$. Genomic DNA was treated with $0.005 \mu \mathrm{g} / \mu \mathrm{L}$ RNase A for $45 \mathrm{~min}$ at $37^{\circ} \mathrm{C}$. $2 \mu \mathrm{L}$ of DNA was added to tubes containing CutSmart buffer with or without Rsal restriction enzyme and incubated at $37^{\circ} \mathrm{C}$ for $2 \mathrm{hrs}$. Quantitative PCR was performed using the Applied Biosystem QuantStudio 6 Flex machine. PowerUp SYBR Green Master Mix was used to quantify resection at MAT1 (0.15kb from DSB) locus. Pre1 was used as a negative control. Rsal cut DNA was normalized to uncut DNA as previously described to quantify the \%ssDNA / total DNA (Ferrari et al. 2015).

\section{qPCR based Ligation Assay}

Cells from each strain were collected from the OCE process and resuspended in $15 \mathrm{ml}$ YPLG. Next, $2.5 \mathrm{~mL}$ of the cells were pelleted as 'No break' sample, and $2 \%$ GAL was added to the remaining cells, to induce a DSB. $2.5 \mathrm{ml}$ of cells were pelleted after $3 \mathrm{hr}$ incubation as timepoint 0 sample. Following that, GAL was washed off and the cells were released in YPAD and respective timepoint samples were collected. Genomic DNA was purified using standard genomic preparation method by isopropanol precipitation and ethanol washing, and DNA was re-suspended in $100 \mathrm{~mL} \mathrm{ddH}_{2} \mathrm{O}$. Quantitative PCR was performed using the Applied Biosystem QuantStudio 6 Flex machine. PowerUp SYBR Green Master Mix was used to quantify resection at HO6 (at DSB) locus. Pre1 was used as a negative control. Signals from the HO6 timepoints were normalized to 'No break' signals and $\%$ Ligation was determined.

\section{Tethering Microscopy}

Cells derived from the parent strain JC-4066 were collected following the OCE process. Cells were resuspended in SCLGg media and cells were treated with 2\% GAL for 2 hours and cell pellets were collected and washed 2 times with PBS. After the final wash, cells were placed on cover slips and imaged using a fully motorized Nikon Ti Eclipse inverted epi-fluorescence microscope. Z-stack images were acquired with $200 \mathrm{~nm}$ increments along the $\mathrm{z}$ plane, using a 60X oil immersion 1.4 N.A. objective. Images were captured with a Hamamatsu Orca flash 4.0 v2 sCMOS 16-bit camera and the system was controlled by Nikon NIS-Element Imaging Software (Version 5.00). All images were deconvolved with Huygens Essential version 18.10 (Scientific Volume Imaging, The Netherlands, http://svi.nl), using the Classic Maximum Likelihood Estimation (CMLE) algorithm, with SNR:40 and 50 iterations. To measure the distance between the GFP and mCherry foci, the ImageJ plug-in Distance Analysis (DiAna) was used (Gilles et al. 2017). Distance measurements represent the shortest distance between the brightest pixel in the mCherry channel and the GFP channel. Each cell was measured individually and > 50 cells were analyzed per condition per biological replicate.

\section{Continuous DSB assay and identification of mutations in survivors}

Cells were grown overnight in YPLG media at $25^{\circ} \mathrm{C}$ to saturation. Cells were collected by centrifugation at 2500rpm for 3 minutes and pellets were washed $1 \mathrm{x}$ in $\mathrm{ddH}_{2} \mathrm{O}$ and re- 
suspended in $\mathrm{dd}_{2} \mathrm{O}$. Cells were counted and spread on YPA plates supplemented with either $2 \%$ GLU or $2 \%$ GAL. On the Glucose plates $1 \times 10^{3}$ total cells were added and on the galactose plates $1 \times 10^{5}$ total cells were added. The cells were incubated for 3-4 days at room temperature and colonies counted on each plate. Survival was determined by normalizing the number of surviving colonies in the GAL plates to number of colonies in the GLU plates. 100 survivors from each strain were scored for the mating type assay as previously described (Sorenson et al. 2017).

\section{Western Blot}

Cells were lysed by re-suspending them in lysis buffer (with PMSF and protease inhibitor cocktail tablets) followed by bead beating. The protein concentration of the whole cell extract was determined using the NanoDrop. Equal amounts of whole cell extract were added to wells of $10 \%$ polyacrylamide SDS gel. After the run, the protein was transferred to Nitrocellulose membrane at $100 \mathrm{~V}$ for $80 \mathrm{mins}$. The membrane was Ponceau stained (which served as a loading control), followed by blocking in $10 \%$ milk-PBST for 1 hour at room temperature. Respective primary antibody solution (1:1000 dilution) was added and left for overnight incubation at $4^{\circ} \mathrm{C}$. The membranes were then washed with PBST and left for 1 hour with secondary antibody. Followed by washing the membranes, adding the ECL substrates and imaging them. 


\section{Figure Legends}

Figure 1. Aged yeast cells have a reduced ability to resect DSBs

(A) Schematic representation of DSB repair pathway choice, where various factors play key roles in the three important processes - DNA end-bridging, end-joining and end-resection. If endbridging and end-joining are active then NHEJ happens, and if end-resection initiates HR happens and NHEJ is no more an option.

(B) Representative image of WT aged yeast cells following old cell enrichment (OCE) stained with calcofluor to identify bud scars in young cells, old cells on day1, day2 and day3.

(C) Scatter plot showing the average number of bud scars counted from aged WT yeast cells as seen in (B) in young cells - $\mathrm{Y}$ and old cells on day1 - O1, day2 - 02 and day3 - O3.

(D) Schematic representation of the $\mathrm{HO}$ cut site on chromosome III used in the qPCR resection assay. The Rsal is $0.15 \mathrm{~kb}$ from the $\mathrm{HO}$ cut site.

(E) WT (JC-727) were aged using the OCE process and collected on young - Y, old day1 - O1, day2 $\mathrm{O} 2$ and day3 - O3. Resection of DNA 0.15kb away from the HO cut site is measured as the percent of single stranded DNA (sSDNA) at 40,80 and 150 minutes following the induction of the DSB. Analysis was performed in triplicate from at least three biological replicate experiments.

(F) Representative image of yeast cells with tethered (co-localized GFP and mCherry) and untethered (distant GFP and mCherry) ends. Scatter plot showing the tethering of DSB ends, as measured by the distance between the GFP and mCherry foci in wild type (JC-4066) Y, O1, O2 and O3 under DSB induction. The Geometric mean (GM) distance for each sample is specified under the respective sample data plot. Significance was determined using Kruskal-Wallis and Dunn's multiple comparison test. All strains compared are marked ( $\left.\mathrm{P}<0.05^{*} ; \mathrm{P}<0.01^{* *} ; \mathrm{P}<0.001^{* * *}\right)$ unless specified with a line, strains are compared to $Y$ cells.

\section{Figure 2. Recruitment of homologous recombination (HR) repair factors during aging}

(A) Model showing the resection steps of homologous recombination. MRX and Ku tether the DSB and Sae2 initiates Mre11 endonuclease short range resection. Initiation of long-range resection leads to removal of $\mathrm{Ku}$ and resection is then carried out by either Exo1 or Sgs1/Dna2.

(B) Enrichment of no tag control (JC-727) and Mre11 ${ }^{\text {HA }}$ (JC-3802) $0.6 \mathrm{~kb}$ away from the DSB at 0 - and 3-hour time point in cells that are young - $Y$ and aged to day 1 - 01 and day 2 - 02 . The fold enrichment is normalised to SMC2 locus.

(C) Enrichment of Rad50 ${ }^{\mathrm{HA}}$ (JC-3306) $0.6 \mathrm{~kb}$ away from the DSB at 0- and 3-hour time point in cells that are $\mathrm{Y}$ and aged to $\mathrm{O} 1$ and 02 . The fold enrichment is normalised to SMC2 locus.

(D) Enrichment of Sae2 ${ }^{\mathrm{HA}}$ (JC-5116), $0.6 \mathrm{~kb}$ away from the DSB at 0 - and 3-hour time point in cells that are $\mathrm{Y}$ and aged to $\mathrm{O1}$. The fold enrichment is normalised to SMC2 locus.

(E) Enrichment of Dna2 ${ }^{\mathrm{HA}}$ (JC-4117) $0.6 \mathrm{~kb}$ away from the DSB at 0- and 3-hour time point in cells that are $Y$ and aged to O1. The fold enrichment is normalised to SMC2 locus.

(F) Enrichment of Sgs1 ${ }^{\mathrm{HA}}$ (JC-4135), 0.6kb away from the DSB at 0- and 3-hour time point in cells that are $Y$ and aged to 01 . The fold enrichment is normalised to SMC2 locus.

(G) Enrichment of Exo1 ${ }^{\mathrm{HA}}$ (JC-4869) 0.6kb away from the DSB at 0- and 3-hour time point in cells that are $\mathrm{Y}$ and aged to $\mathrm{O} 1$. The fold enrichment is normalised to SMC2 locus 
For all the experiments - error bars represent the standard error of three replicates. Significance was determined using 1-tailed, unpaired Student's t test. All strains compared are marked $\left(\mathrm{P}<0.05^{*} ; \mathrm{P}<0.01^{* *} ; \mathrm{P}<0.001^{* * *}\right)$ unless specified with a line, strains are compared to $\mathrm{Y}$ cells.

\section{Figure 3. Non homologous end joining (NHEJ) in aging cells}

(A) Enrichment of Ku70 ${ }^{\mathrm{Flag}}$ (JC-3964) $0.6 \mathrm{~kb}$ away from the DSB at 0- and 3-hour time point in cells that are young, aged to day 1 and day 2 . The fold enrichment is normalised to SMC2 locus.

(B) Enrichment of $\mathrm{Nej}^{\text {Myc }}$ (JC-1687) $0.6 \mathrm{~kb}$ away from the DSB at 0- and 3-hour time point in cells that are young, aged to day 1 and day 2. The fold enrichment is normalised to SMC2 locus.

(C) Schematic of qPCR ligation assay of the HO cut site on chromosome III. Following the DSB cells were released into glucose to allow repair by non-homologous end-joining (NHEJ) and ligated ends were qPCR amplified using the primers around the cut site.

(D) WT (JC-727) and ku70 (JC-1904), were aged using the OCE process. Ligation of DNA at the HO cut site is measured as the percent of ligation at $0,40,80$ and 150 minutes following the release into glucose.

(E) Resection of DNA $0.15 \mathrm{~kb}$ away from the $\mathrm{HO}$ cut sit is measured as the percent of single stranded DNA (ssDNA) at $0,40,80$ and 150 minutes following the induction of the DSB. WT (JC-727), nej1A (JC-1342), ku70 (JC-1904) and $d n / 4 \Delta$ (JC-3290) were aged using the OCE process and collected on old day1.

For all the experiments - error bars represent the standard error of three replicates. Significance was determined using 1-tailed, unpaired Student's $t$ test. All strains compared are marked $\left(\mathrm{P}<0.05^{*} ; \mathrm{P}<0.01^{* *} ; \mathrm{P}<0.001^{* * *}\right)$ unless specified with a line, strains are compared to $\mathrm{Y}$ cells.

\section{Figure 4. Relocation of double strand breaks (DSBs) in aged cells}

(A) Schematic of nuclear periphery microscopy with GFP tagged double strand break and CFP tagged Nup49. Z stacks were used to determine if the DSB is in contact with the nuclear periphery

(B) 2D and 3D Reconstruction of nuclear periphery using IMARIS showing the DSB ${ }^{\text {GFP }}$ and Nup49 ${ }^{\text {CFP }}$.

(C) Percentage of WT (JC-3013) young and aged day 1 old cells with the DSB touching the nuclear periphery

(D) Model of DSB re-localization to Mps3 to repair by homologous recombination (HR) or the nuclear pore complex to repair by alt-EJ (microhomology-mediated end joining)

(E) Enrichment of Mps3 $3^{\mathrm{Ha}}$ (JC-3167) $0.6 \mathrm{~kb}$ away from the DSB at 0 - and 3-hour time point in cells that are $\mathrm{Y}$ and aged to $\mathrm{O} 1$ and 02 . The fold enrichment is normalised to SMC2 locus.

(F) Enrichment of Nup133 ${ }^{\mathrm{Myc}}$ (JC-1510) $0.6 \mathrm{~kb}$ away from the DSB at 0- and 3-hour time point in cells that are $\mathrm{Y}$ and aged to $\mathrm{O} 1$ and $\mathrm{O} 2$. The fold enrichment is normalised to SMC2 locus. 


\section{References}

Cejka P (2015) DNA End Resection: Nucleases Team Up with the Right Partners to Initiate Homologous Recombination. J. Biol. Chem. 290, 22931-22938.

Chiolo I, Minoda A, Colmenares SU, Polyzos A, Costes SV \& Karpen GH (2011) Double-Strand Breaks in Heterochromatin Move Outside of a Dynamic HP1a Domain to Complete Recombinational Repair. Cell 144, 732-744.

Chung I \& Zhao X (2015) DNA break-induced sumoylation is enabled by collaboration between a SUMO ligase and the ssDNA-binding complex RPA. Genes Dev. 29, 1593-1598.

Churikov D, Charifi F, Eckert-Boulet N, Silva S, Simon M-N, Lisby M \& Géli V (2016) SUMO-Dependent Relocalization of Eroded Telomeres to Nuclear Pore Complexes Controls Telomere Recombination. Cell Rep. 15, 1242-1253.

Ciccia A \& Symington LS (2016) Stressing Out About RAD52. Mol. Cell 64, 1017-1019.

Connolly B, White Cl \& Haber JE (1988) Physical monitoring of mating type switching in Saccharomyces cerevisiae. Mol. Cell. Biol. 8, 2342-2349.

Delabaere L, Ertl HA, Massey DJ, Hofley CM, Sohail F, Bienenstock EJ, Sebastian H, Chiolo I \& LaRocque JR (2017) Aging impairs double-strand break repair by homologous recombination in Drosophila germ cells. Aging Cell 16, 320-328.

Denoth Lippuner A, Julou T \& Barral Y (2014) Budding yeast as a model organism to study the effects of age. FEMS Microbiol. Rev. 38, 300-325.

Ferrari M, Dibitetto D, De Gregorio G, Eapen VV, Rawal CC, Lazzaro F, Tsabar M, Marini F, Haber JE \& Pellicioli A (2015) Functional Interplay between the 53BP1-Ortholog Rad9 and the Mre11 Complex Regulates Resection, End-Tethering and Repair of a Double-Strand Break. PLoS Genet. 11, e1004928.

Ganley ARD \& Kobayashi T (2014) Ribosomal DNA and cellular senescence: new evidence supporting the connection between rDNA and aging. FEMS Yeast Res. 14, 49-59.

Gilles J-F, Dos Santos M, Boudier T, Bolte S \& Heck N (2017) DiAna, an ImageJ tool for object-based 3D co-localization and distance analysis. Methods 115, 55-64.

Gorbunova V \& Seluanov A (2016) DNA double strand break repair, aging and the chromatin connection. Mutat. Res. Mol. Mech. Mutagen. 788, 2-6.

He C, Zhou C \& Kennedy BK (2018) The yeast replicative aging model. Biochim. Biophys. Acta BBA - Mol. Basis Dis. 1864, 2690-2696.

Hoeijmakers JHJ (2009) DNA Damage, Aging, and Cancer. N. Engl. J. Med. 361, 1475-1485. 
Hohl M, Kochańczyk T, Tous C, Aguilera A, Krężel A \& Petrini JHJ (2015) Interdependence of the Rad50 hook and globular domain functions. Mol. Cell 57, 479-491.

Hohl M, Mojumdar A, Hailemariam S, Kuryavyi V, Ghisays F, Sorenson K, Chang M, Taylor BS, Patel DJ, Burgers PM, Cobb JA \& Petrini JHJ (2020) Modeling cancer genomic data in yeast reveals selection against ATM function during tumorigenesis. PLoS Genet. 16, e1008422.

Horigome C, Bustard DE, Marcomini I, Delgoshaie N, Tsai-Pflugfelder M, Cobb JA \& Gasser SM (2016) PolySUMOylation by Siz2 and Mms21 triggers relocation of DNA breaks to nuclear pores through the SIx5/SIx8 STUbL. Genes Dev. 30, 931-945.

Horigome C, Oma Y, Konishi T, Schmid R, Marcomini I, Hauer MH, Dion V, Harata M \& Gasser SM (2014) SWR1 and INO80 Chromatin Remodelers Contribute to DNA Double-Strand Break Perinuclear Anchorage Site Choice. Mol. Cell 55, 626-639.

Hu Z, Chen K, Xia Z, Chavez M, Pal S, Seol J-H, Chen C-C, Li W \& Tyler JK (2014) Nucleosome loss leads to global transcriptional up-regulation and genomic instability during yeast aging. Genes Dev. 28, 396-408.

Janssens G \& Veenhoff L (2016) Evidence for the hallmarks of human aging in replicatively aging yeast. Microb. Cell 3, 263-274.

Jasin M \& Haber JE (2016) The Democratization of Gene Editing: Insights from site-specific cleavage and double-strand break repair. DNA Repair 44, 6-16.

Ju Y-J, Lee K-H, Park J-E, Yi Y-S, Yun M-Y, Ham Y-H, Kim T-J, Choi HM, Han GJ, Lee J-H, Lee J, Han JS, Lee KM \& Park G-H (2006) Decreased expression of DNA repair proteins Ku70 and Mre11 is associated with aging and may contribute to the cellular senescence. Exp. Mol. Med. 38, 686-693.

Kadyk LC \& Hartwell LH (1992) Sister chromatids are preferred over homologs as substrates for recombinational repair in Saccharomyces cerevisiae. Genetics 132, 387-402.

Kalocsay M, Hiller NJ \& Jentsch S (2009) Chromosome-wide Rad51 Spreading and SUMO-H2A.ZDependent Chromosome Fixation in Response to a Persistent DNA Double-Strand Break. Mol. Cell 33, 335-343.

Khadaroo B, Teixeira MT, Luciano P, Eckert-Boulet N, Germann SM, Simon MN, Gallina I, Abdallah P, Gilson E, Géli V \& Lisby M (2009) The DNA damage response at eroded telomeres and tethering to the nuclear pore complex. Nat. Cell Biol. 11, 980-987.

Kubben N \& Misteli T (2017) Shared molecular and cellular mechanisms of premature ageing and ageingassociated diseases. Nat. Rev. Mol. Cell Biol. 18, 595-609.

Lans H \& Hoeijmakers JHJ (2006) Cell biology: ageing nucleus gets out of shape. Nature 440, 32-34.

Lindstrom DL \& Gottschling DE (2009) The Mother Enrichment Program: A Genetic System for Facile Replicative Life Span Analysis in Saccharomyces cerevisiae. Genetics 183, 413-422. 
Loeillet S, Palancade B, Cartron M, Thierry A, Richard G-F, Dujon B, Doye V \& Nicolas A (2005) Genetic network interactions among replication, repair and nuclear pore deficiencies in yeast. DNA Repair 4, 459-468.

Ma J-L, Kim EM, Haber JE \& Lee SE (2003) Yeast Mre11 and Rad1 Proteins Define a Ku-Independent Mechanism To Repair Double-Strand Breaks Lacking Overlapping End Sequences. Mol. Cell. Biol. $23,8820-8828$.

Mao Z, Tian X, Van Meter M, Ke Z, Gorbunova V \& Seluanov A (2012) Sirtuin 6 (SIRT6) rescues the decline of homologous recombination repair during replicative senescence. Proc. Natl. Acad. Sci. U. S. A. 109, 11800-11805.

Mayer PJ, Lange CS, Bradley MO \& Nichols WW (1989) Age-dependent decline in rejoining of X-rayinduced DNA double-strand breaks in normal human lymphocytes. Mutat. Res. 219, 95-100.

McVey M \& Lee SE (2008) MMEJ repair of double-strand breaks (director's cut): deleted sequences and alternative endings. Trends Genet. TIG 24, 529-538.

Mimitou EP \& Symington LS (2010) Ku prevents Exo1 and Sgs1-dependent resection of DNA ends in the absence of a functional MRX complex or Sae2. EMBO J. 29, 3358-3369.

Mimitou EP \& Symington LS (2008) Sae2, Exo1 and Sgs1 collaborate in DNA double-strand break processing. Nature 455, 10.1038/nature07312.

Mojumdar A, Adam N \& Cobb J (2022a) Multifunctional properties of Nej1XLF C-terminus promote endjoining and impact DNA double-strand break repair pathway choice. , 2022.01.13.476264. Available at: https://www.biorxiv.org/content/10.1101/2022.01.13.476264v1 [Accessed January 30, 2022].

Mojumdar A, Adam N \& Cobb JA (2022b) Nej1XLF interacts with Sae2CTIP to inhibit Dna2 mediated resection at DNA double strand break. , 2021.04.10.439283. Available at: https://www.biorxiv.org/content/10.1101/2021.04.10.439283v4 [Accessed January 30, 2022].

Mojumdar A, Sorenson K, Hohl M, Toulouze M, Lees-Miller SP, Dubrana K, Petrini JHJ \& Cobb JA (2019) Nej1 Interacts with Mre11 to Regulate Tethering and Dna2 Binding at DNA Double-Strand Breaks. Cell Rep. 28, 1564-1573.e3.

Moore JK \& Haber JE (1996) Capture of retrotransposon DNA at the sites of chromosomal double-strand breaks. Nature 383, 644-646.

Mortimer RK \& Johnston JR (1959) Life Span of Individual Yeast Cells. Nature 183, 1751-1752.

Nagai S, Dubrana K, Tsai-Pflugfelder M, Davidson MB, Roberts TM, Brown GW, Varela E, Hediger F, Gasser SM \& Krogan NJ (2008) Functional Targeting of DNA Damage to a Nuclear PoreAssociated SUMO-Dependent Ubiquitin Ligase. Science 322, 597-602.

Niedernhofer L, Gurkar AU, Wang Y, Vijg J, Hoeijmakers JHJ \& Robbins PD (2018) Nuclear Genomic Instability and Aging. Annu. Rev. Biochem. 87, 295-322. 
Oza P, Jaspersen SL, Miele A, Dekker J \& Peterson CL (2009) Mechanisms that regulate localization of a DNA double-strand break to the nuclear periphery. Genes Dev. 23, 912-927.

Pal S, Postnikoff SD, Chavez M \& Tyler JK (2018) Impaired cohesion and homologous recombination during replicative aging in budding yeast. Sci. Adv. 4, eaaq0236.

Pannunzio NR, Li S, Watanabe G \& Lieber MR (2014) Non-homologous end joining often uses microhomology: implications for alternative end joining. DNA Repair 17, 74-80.

Rempel IL, Steen A \& Veenhoff LM (2020) Poor old pores-The challenge of making and maintaining nuclear pore complexes in aging. FEBS J. 287, 1058-1075.

Ryu T, Spatola B, Delabaere L, Bowlin K, Hopp H, Kunitake R, Karpen GH \& Chiolo I (2015) Heterochromatic breaks move to the nuclear periphery to continue recombinational repair. Nat. Cell Biol. 17, 1401-1411.

Seluanov A, Danek J, Hause N \& Gorbunova V (2007) Changes in the level and distribution of Ku proteins during cellular senescence. DNA Repair 6, 1740-1748.

Sinclair DA (2013) Studying the Replicative Life Span of Yeast Cells. In T. O. Tollefsbol, ed. Biological Aging. Methods in Molecular Biology. Totowa, NJ: Humana Press, pp.49-63. Available at: http://link.springer.com/10.1007/978-1-62703-556-9_5 [Accessed May 5, 2020].

Singh NP, Danner DB, Tice RR, Brant L \& Schneider EL (1990) DNA damage and repair with age in individual human lymphocytes. Mutat. Res. 237, 123-130.

Sinha S, Villarreal D, Shim EY \& Lee SE (2016) Risky Business: Microhomology-Mediated End Joining. Mutat. Res. 788, 17-24.

Sorenson KS, Mahaney BL, Lees-Miller SP \& Cobb JA (2017) The non-homologous end-joining factor Nej1 inhibits resection mediated by Dna2-Sgs1 nuclease-helicase at DNA double strand breaks. J. Biol. Chem. 292, 14576-14586.

Su XA, Dion V, Gasser SM \& Freudenreich CH (2015) Regulation of recombination at yeast nuclear pores controls repair and triplet repeat stability. Genes Dev. 29, 1006-1017.

Therizols P, Fairhead C, Cabal GG, Genovesio A, Olivo-Marin J-C, Dujon B \& Fabre E (2006) Telomere tethering at the nuclear periphery is essential for efficient DNA double strand break repair in subtelomeric region. J. Cell Biol. 172, 189-199.

Titus S, Li F, Stobezki R, Akula K, Unsal E, Jeong K, Dickler M, Robson M, Moy F, Goswami S \& Oktay K (2013) Impairment of BRCA1-related DNA double-strand break repair leads to ovarian aging in mice and humans. Sci. Transl. Med. 5, 172 ra21.

Trovesi C, Falcettoni M, Lucchini G, Clerici M \& Longhese MP (2011) Distinct Cdk1 requirements during single-strand annealing, noncrossover, and crossover recombination. PLoS Genet. 7, e1002263. 
Um JH, Kim SJ, Kim DW, Ha MY, Jang JH, Kim DW, Chung BS, Kang CD \& Kim SH (2003) Tissue-specific changes of DNA repair protein Ku and mtHSP70 in aging rats and their retardation by caloric restriction. Mech. Ageing Dev. 124, 967-975.

Valencia-Burton M, Oki M, Johnson J, Seier TA, Kamakaka R \& Haber JE (2006) Different mating-typeregulated genes affect the DNA repair defects of Saccharomyces RAD51, RAD52 and RAD55 mutants. Genetics 174, 41-55.

Vrsanská M, Krátký Z, Biely P \& Machala S (1979) Chitin structures of the cell walls of synchronously grown virgin cells of Saccharomyces cerevisiae. Z. Allg. Mikrobiol. 19, 357-362.

Wu D, Topper LM \& Wilson TE (2008) Recruitment and Dissociation of Nonhomologous End Joining Proteins at a DNA Double-Strand Break in Saccharomyces cerevisiae. Genetics 178, 1237-1249.

Young TZ, Liu P, Urbonaite G \& Acar M (2019) Quantitative Insights into Age-Associated DNA-Repair Inefficiency in Single Cells. Cell Rep. 28, 2220-2230.e7.

Zahid S, Seif El Dahan M, lehI F, Fernandez-Varela P, Le Du M-H, Ropars V \& Charbonnier JB (2021) The Multifaceted Roles of Ku70/80. Int. J. Mol. Sci. 22, 4134.

Zhu Z, Chung W-H, Shim EY, Lee SE \& Ira G (2008) Sgs1 helicase and two nucleases Dna2 and Exo1 resect DNA double strand break ends. Cell 134, 981-994. 
A

DNA DSB
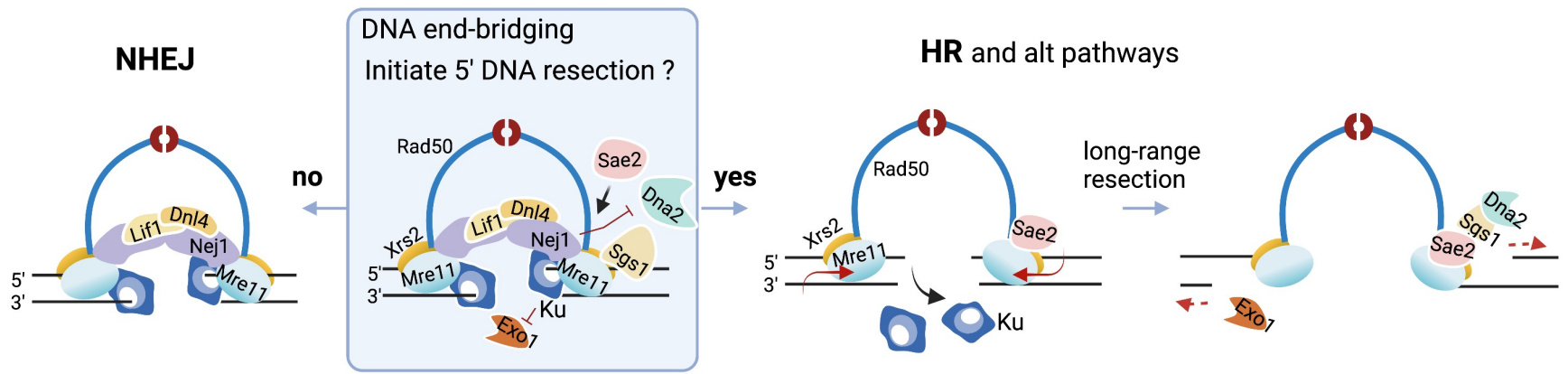

B

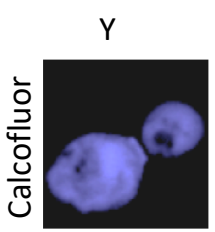

01

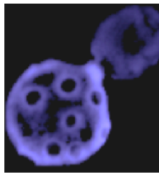

no resection

D
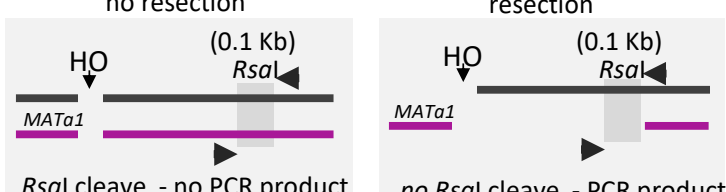

no Rsal cleave - PCR product
C 30 Cell divisions during OCE

17

11

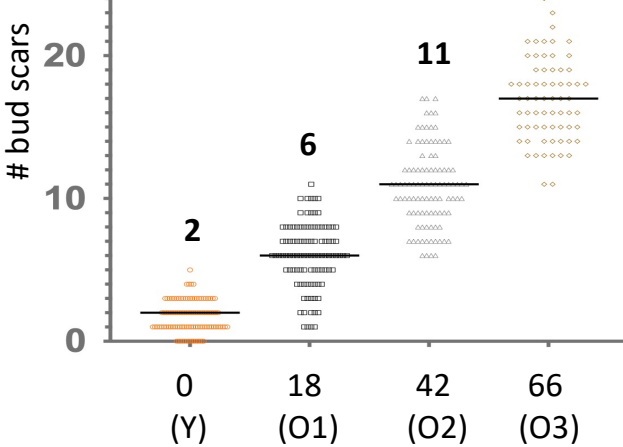

time after initial inoculation (hrs)
E

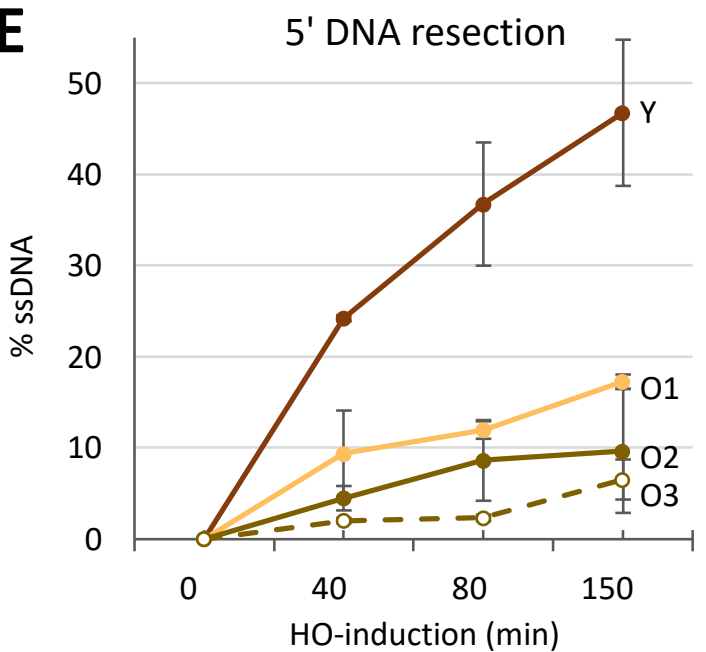

$\mathbf{F}$

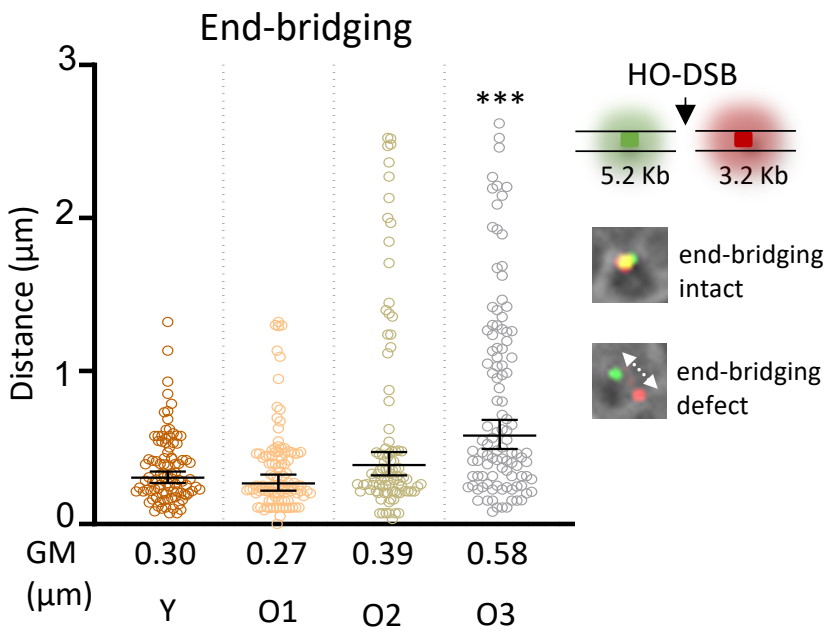

Fig. 1 

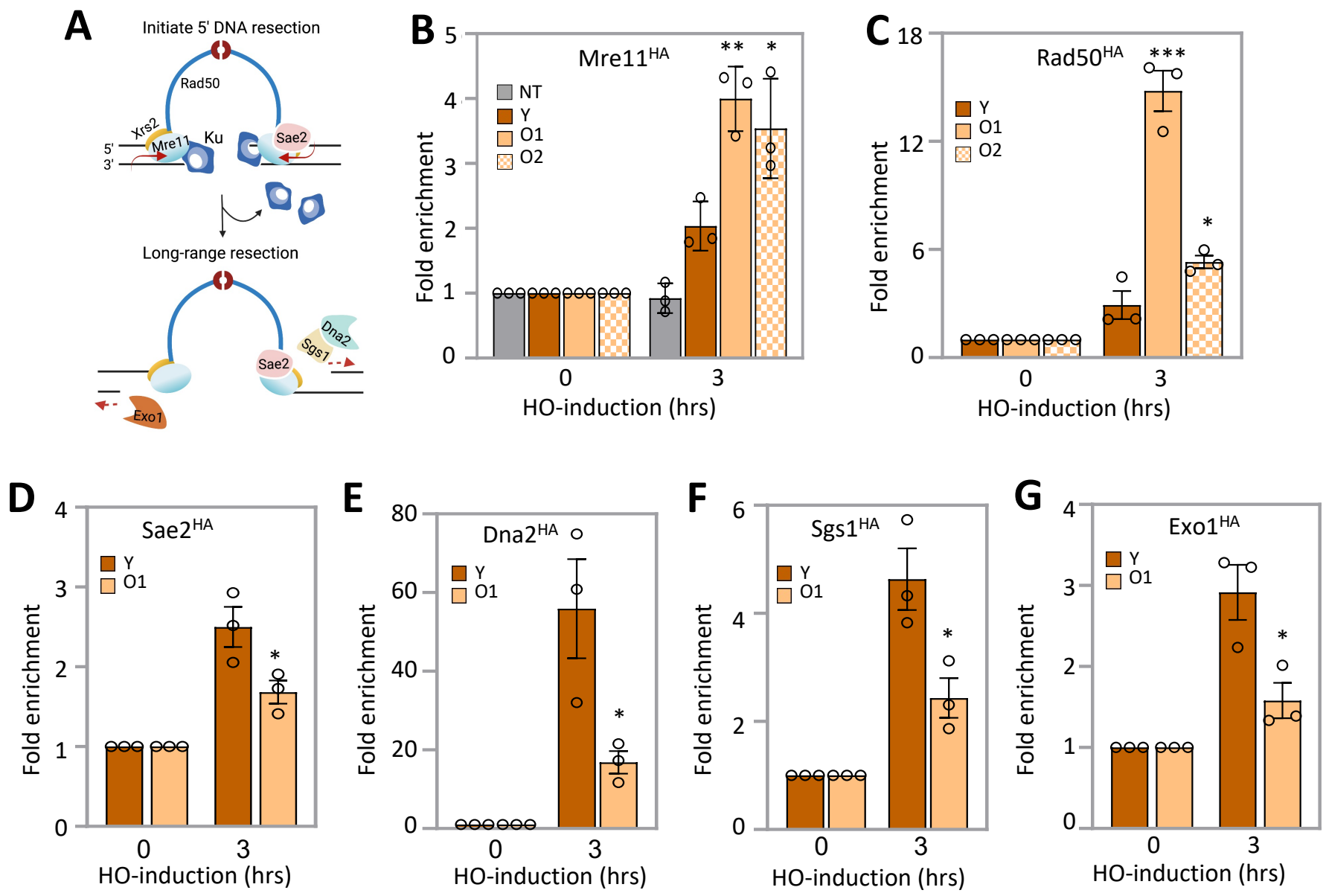

Fig. 2 


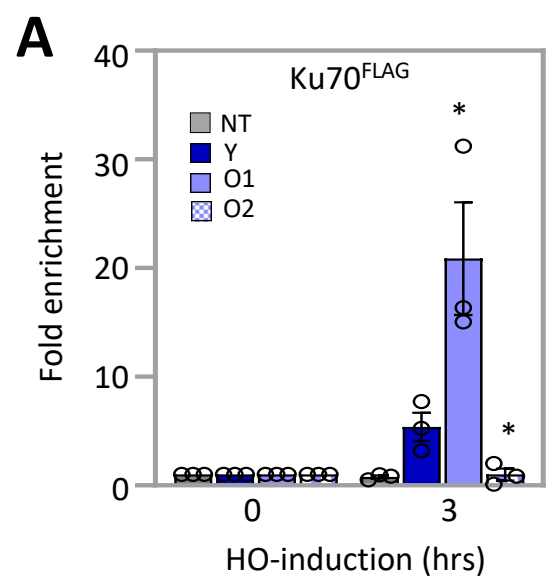

C

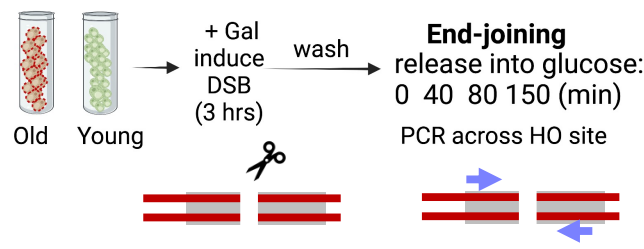

E

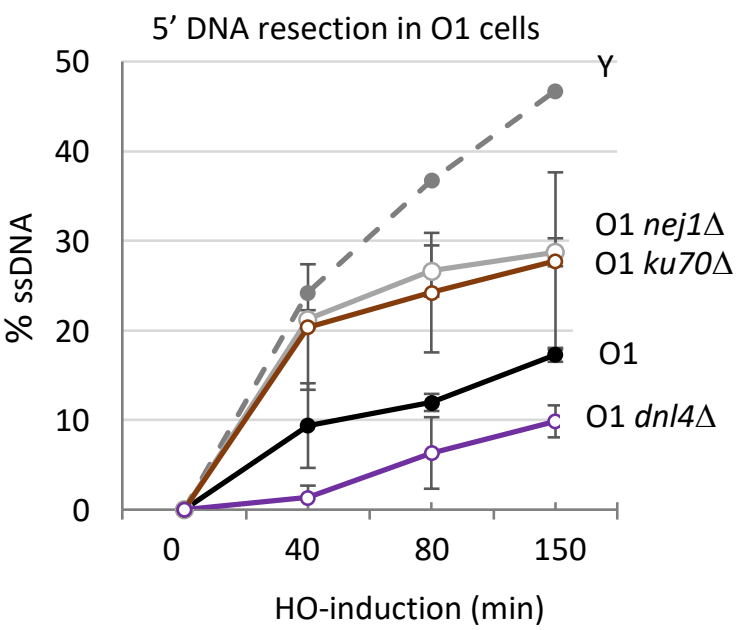

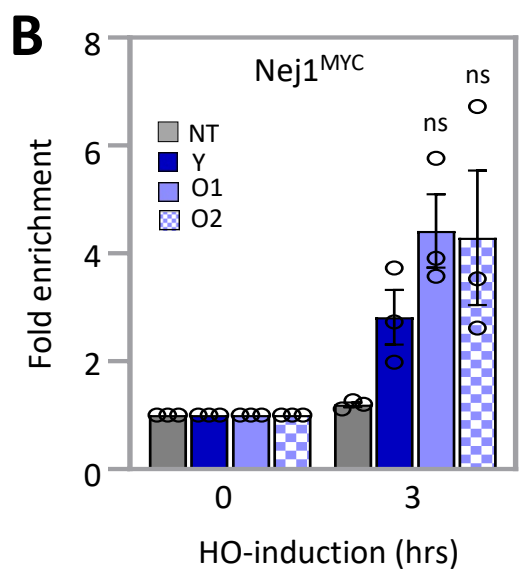

D

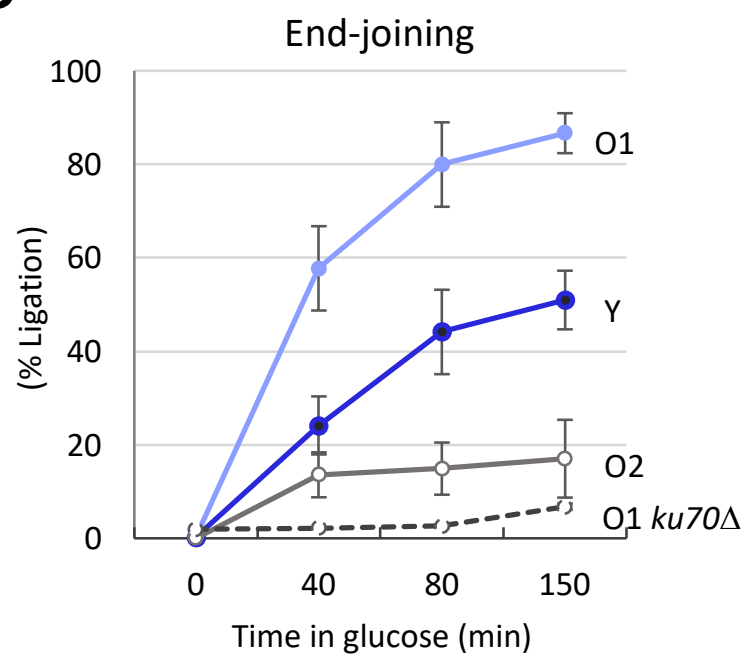

Fig. 3 
A

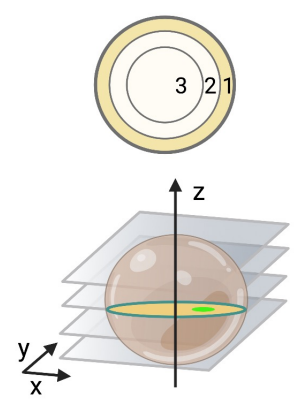

touching periphery?

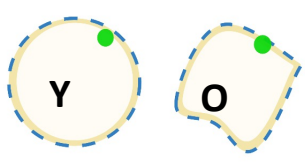

D

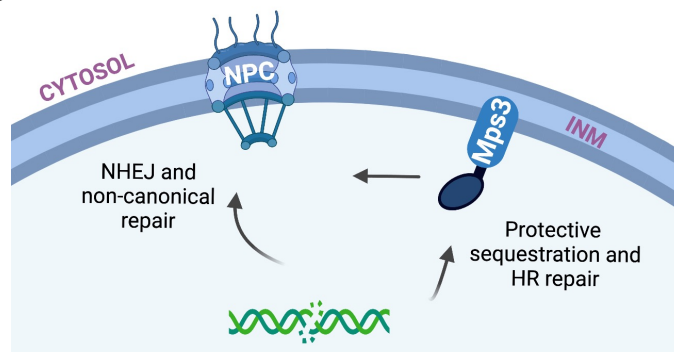

B
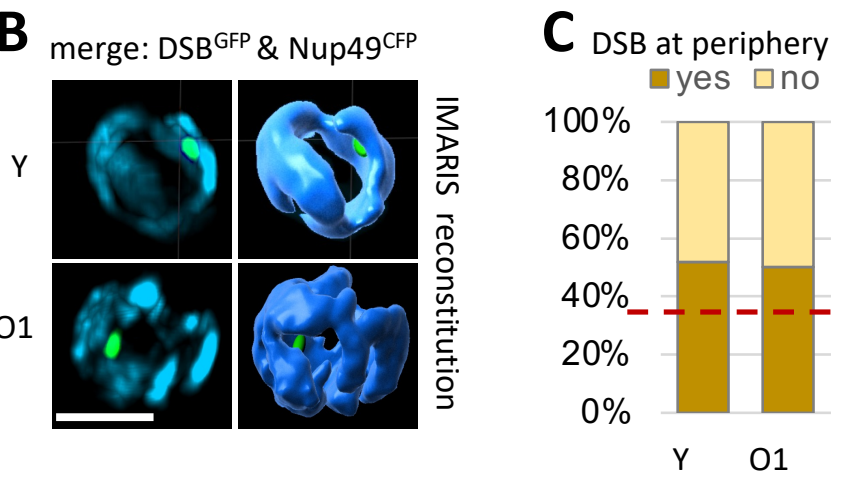

E
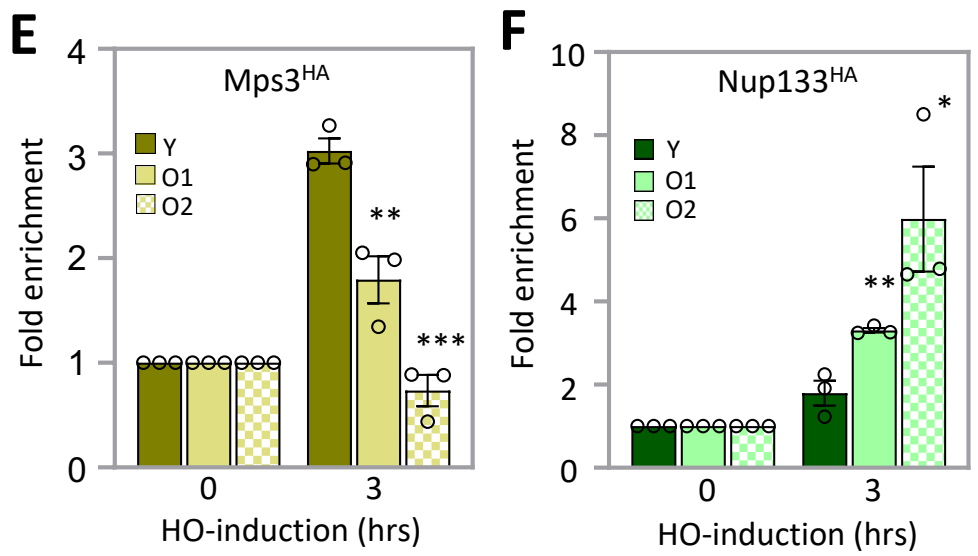

Fig. 4 
Table 1: Mutation Frequency in Survivors

\begin{tabular}{|c|c|c|}
\hline Events & Young & \# (total) \\
\hline$+\mathrm{CA}$ & ...GCGCAACACAGTATAA... & $5(15)$ \\
\hline$-A C A$ & ...GCGCA(ACA)GTATAA... & $5(15)$ \\
\hline$+C$ & ...GCGCAACCAGTATAA... & $2(15)$ \\
\hline$-A$ & ...GCGC(A)ACAGTATAA... & $3(15)$ \\
\hline \multicolumn{3}{|c|}{ Old 1 (6 divisions) } \\
\hline$+\mathrm{CA}$ & ...GCGCAACACAGTATAA... & $5(25)$ \\
\hline$-A C A$ & ...GCGCA(ACA)GTATAA... & $13(25)$ \\
\hline$+\mathrm{C}$ & ...GCGCAACCAGTATAA... & $5(25)$ \\
\hline$-A$ & ...GCGC(A)ACAGTATAA... & $1(25)$ \\
\hline$-G C A$ & ...GC(GCA)ACAGTATAA... & $1(25)$ \\
\hline \multicolumn{3}{|c|}{ Old 2 (11 divisions) } \\
\hline$-A C A$ & $\ldots$...GCGCA(ACA)GTATAA... & $4(25)$ \\
\hline -ACAGT & ...GCGCA(ACAGT)ATAA... & $10(25)$ \\
\hline -GCAA & ....CTTCGC(GCAA)CAGTATAA... & $5(25)$ \\
\hline -CAGTAT & ...GCGCAA(CAGTAT)AATTTT... & $2(25)$ \\
\hline -GT & ...GCGCAACA(GT)ATAATTTT... & $2(25)$ \\
\hline -GCGCAA & ...CTTC(GCGCAA)CAGTATAA... & $1(25)$ \\
\hline -GTATA & ...GCGCAACA(GTATA)ATTTT... & $1(25)$ \\
\hline
\end{tabular}

Insertions in young and Old 1 are highlighted in green, deletions are highlighted in red and are in brackets, micro-homologies are highlighted in bold blue. 
A

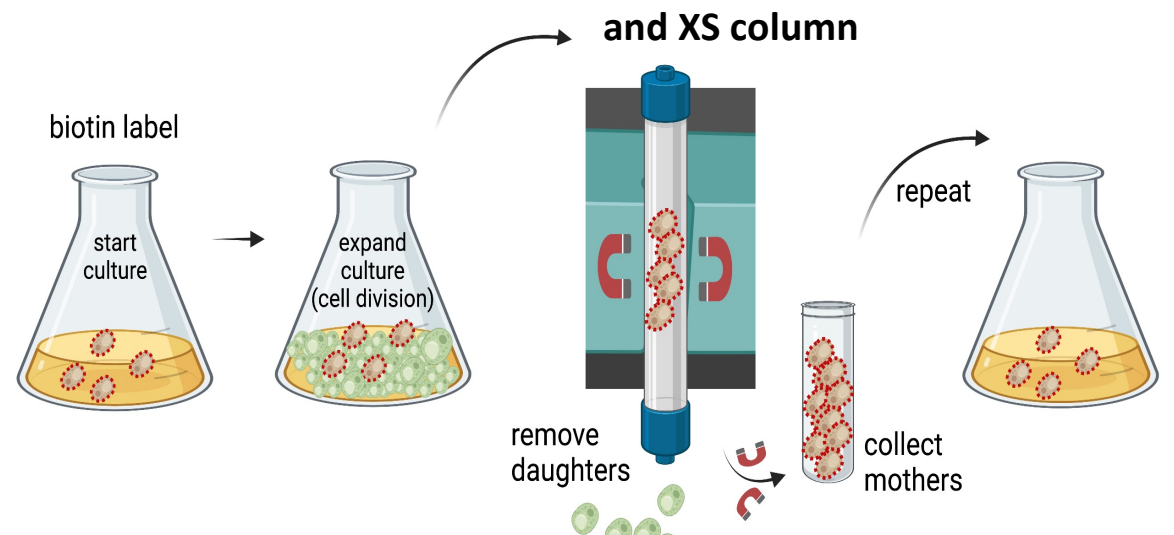

B

\section{Yeast culture of cells}

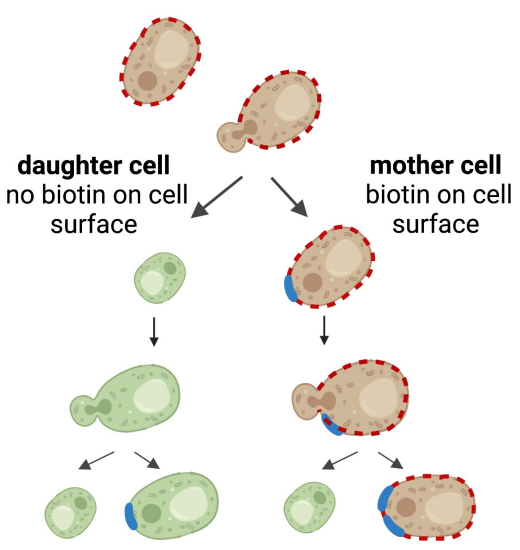

C

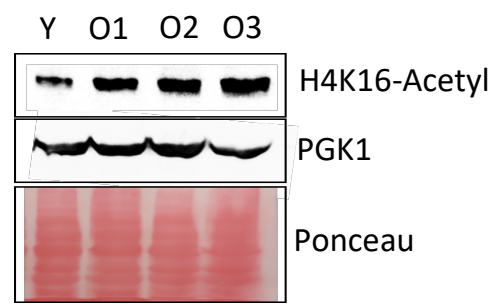

D

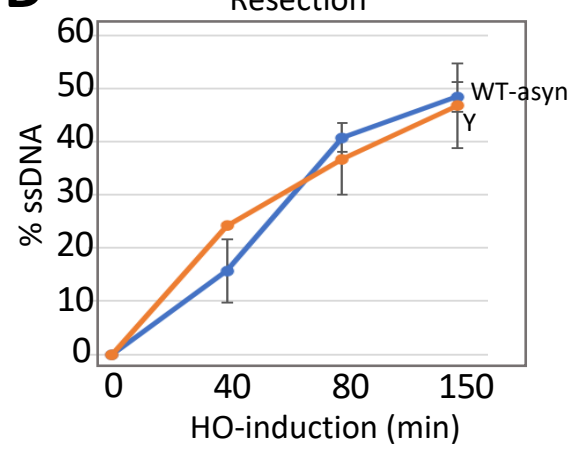

E

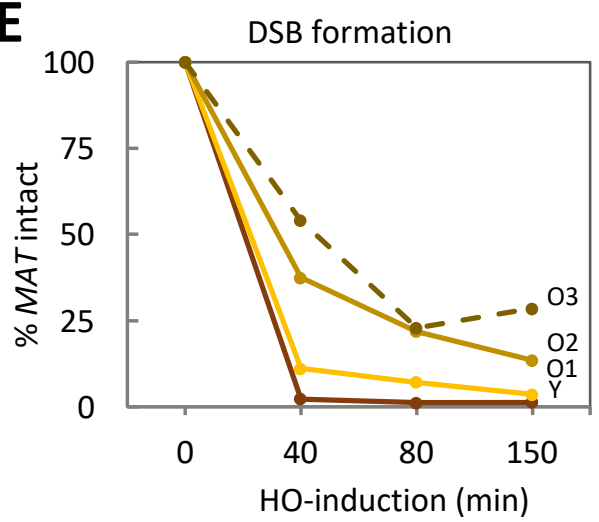

G

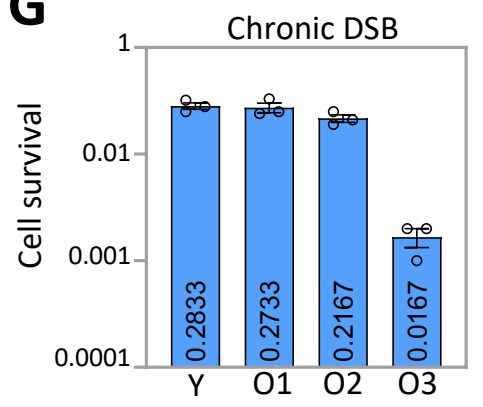

G1: $\quad 67.8 \%$

S/G2: $29.3 \%$

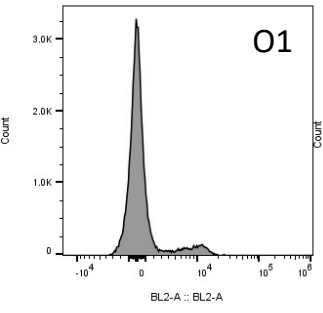

$76.8 \%$

$20.4 \%$

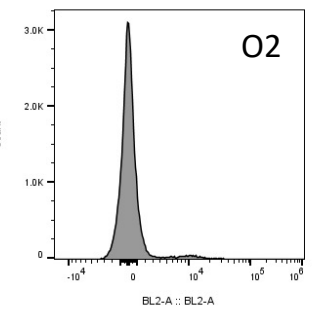

$82.6 \%$

$13.9 \%$

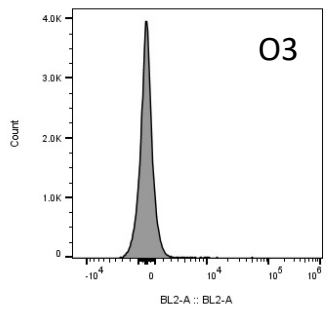

$84.9 \%$

$9.54 \%$ 
Figure S1: Process of old cell enrichment. Related to Figure 1.

(A) Model of old cell enrichment (OCE) used to collect Old day 1 , day 2 and day 3 cells. Cultures are biotin labelled in order to label the mother cells. Mother cells are then used to inoculate an overnight culture of SC media. The mother and daughter culture is then separated over a SuperMACS ${ }^{\mathrm{TM}}$ magnet. The mother cells can then be reinoculated to allow further aging.

(B) Model depicting the biotin labelling of mother cells. This is achieved as the cell wall of daughter cells has brand new cell wall material that is not passed on from the mother cell, therefore the biotin labelling is contained within the cell wall of only the mother.

(C) Western blot of WT cells (JC-727) showing the expression of H4K16 acetylation in young, O1, $\mathrm{O} 2$ and $\mathrm{O} 3$ following old cell enrichment.

(D) Resection of DNA $0.15 \mathrm{~kb}$ away from the $\mathrm{HO}$ cut site is measured as the percent of single stranded DNA (ssDNA) at 0, 40, 80 and 150 minutes following the induction of the DSB. Strains used were Wild Type - WT (JC-727) without any processing and Young - Y (JC-727) that went through the OCE process.

(E) WT cells (JC-727) were aged using the OCE process and collected on young, old day1, day2 and day3. The efficiency of the HO cut was measured by measuring the percentage of MAT that was still intact following induction at $0,40,80$ and 150 minutes.

(F) Fluorescence activated cell sorting (FACS) flow cytometric profile of young and old day 1 , day 2 and day 3 cells, with the fraction of cells in $G 1$ and S/G2 cell cycle phase.

(G) Percentage cell survival upon chronic $\mathrm{HO}$ induction in $\mathrm{Y}$ and $\mathrm{O1}, \mathrm{O} 2, \mathrm{O} 3$-aged cells. 
A
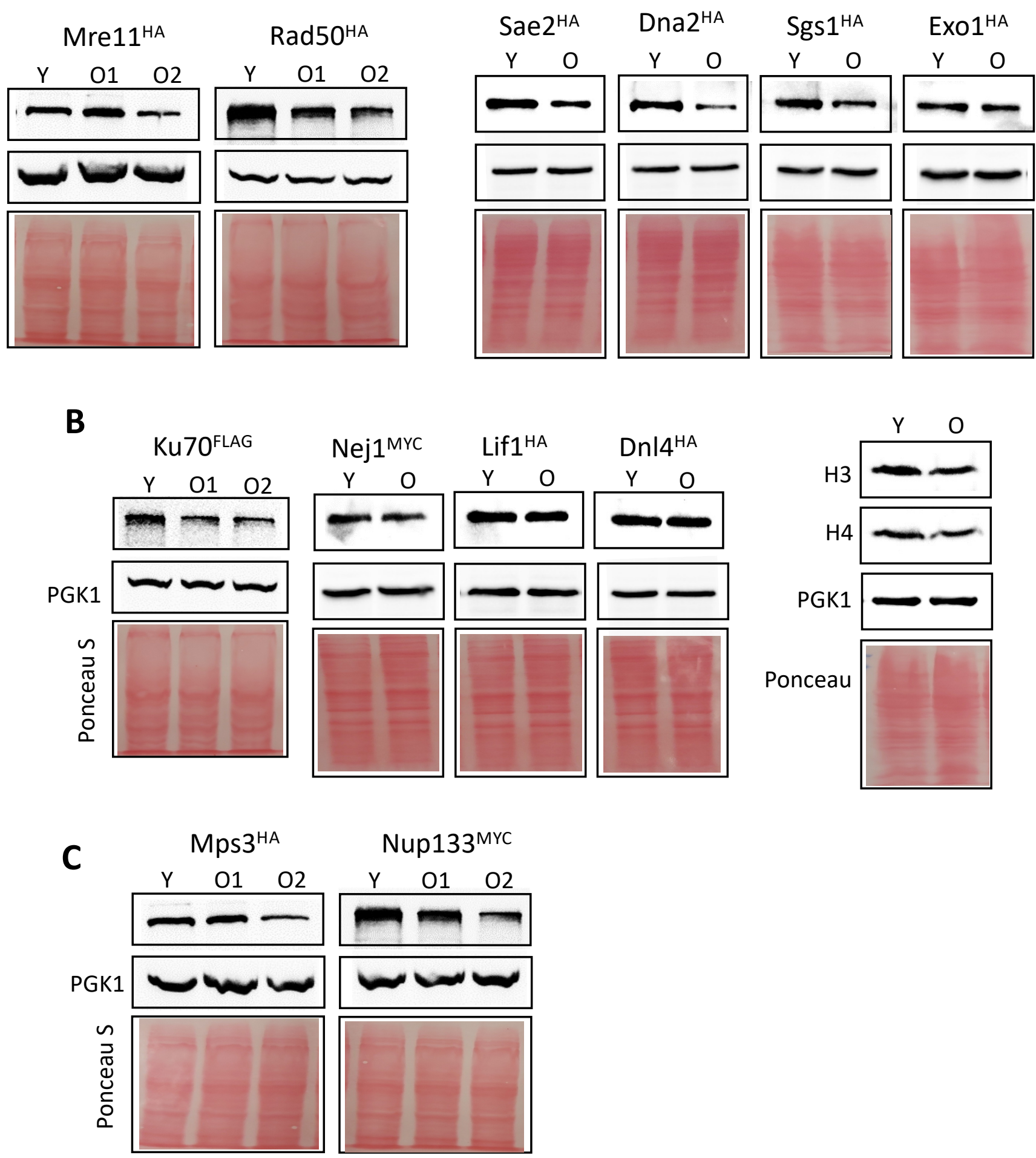

Figure S2: Western blot analysis of DSB repair factors. Related to Figure 2, 3 and 4.

(A-C) Expression of DSB repair proteins in young and old cells determined by western blots. The strains used were WT (JC-727) for H3/4, Mre11 ${ }^{\mathrm{HA}}$ (JC-3802), Rad50 ${ }^{\mathrm{HA}}$ (JC-3306), Sae $2^{\mathrm{HA}}$ (JC5116), Dna2 ${ }^{\mathrm{HA}}$ (JC-4117), Sgs $1^{\mathrm{HA}}$ (JC-4135), Exo1 ${ }^{\mathrm{HA}}$ (JC-4869), Ku70 ${ }^{\text {FLAG }}$ (JC-3964), Nej1 ${ }^{\mathrm{MYC}}$ (JC1687), Lif1 ${ }^{\mathrm{HA}}$ (JC-3319), Dnl4 ${ }^{\mathrm{HA}}$ (JC-5672), Mps3 ${ }^{\mathrm{HA}}$ (JC-3167), Nup133 ${ }^{\mathrm{MYC}}$ (JC-1510). PGK1 and Ponceau staining was used as a loading control. 


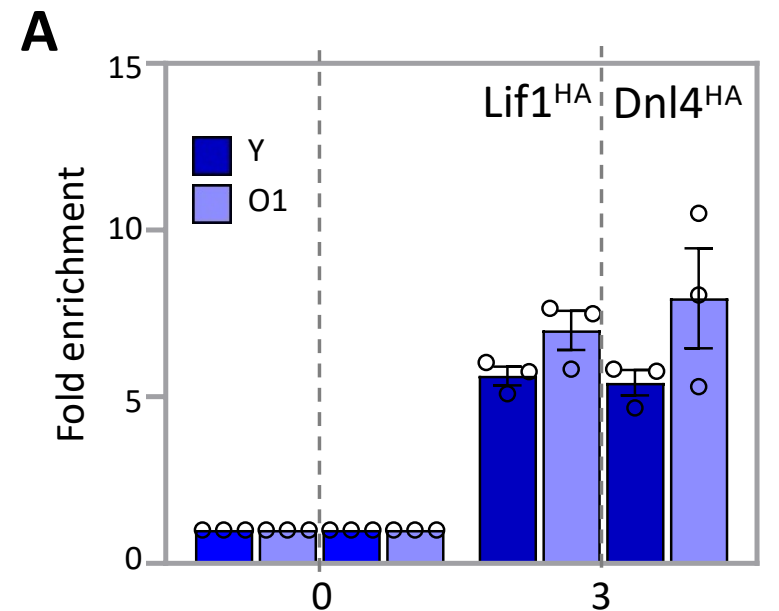

Time in Galactose (hrs)
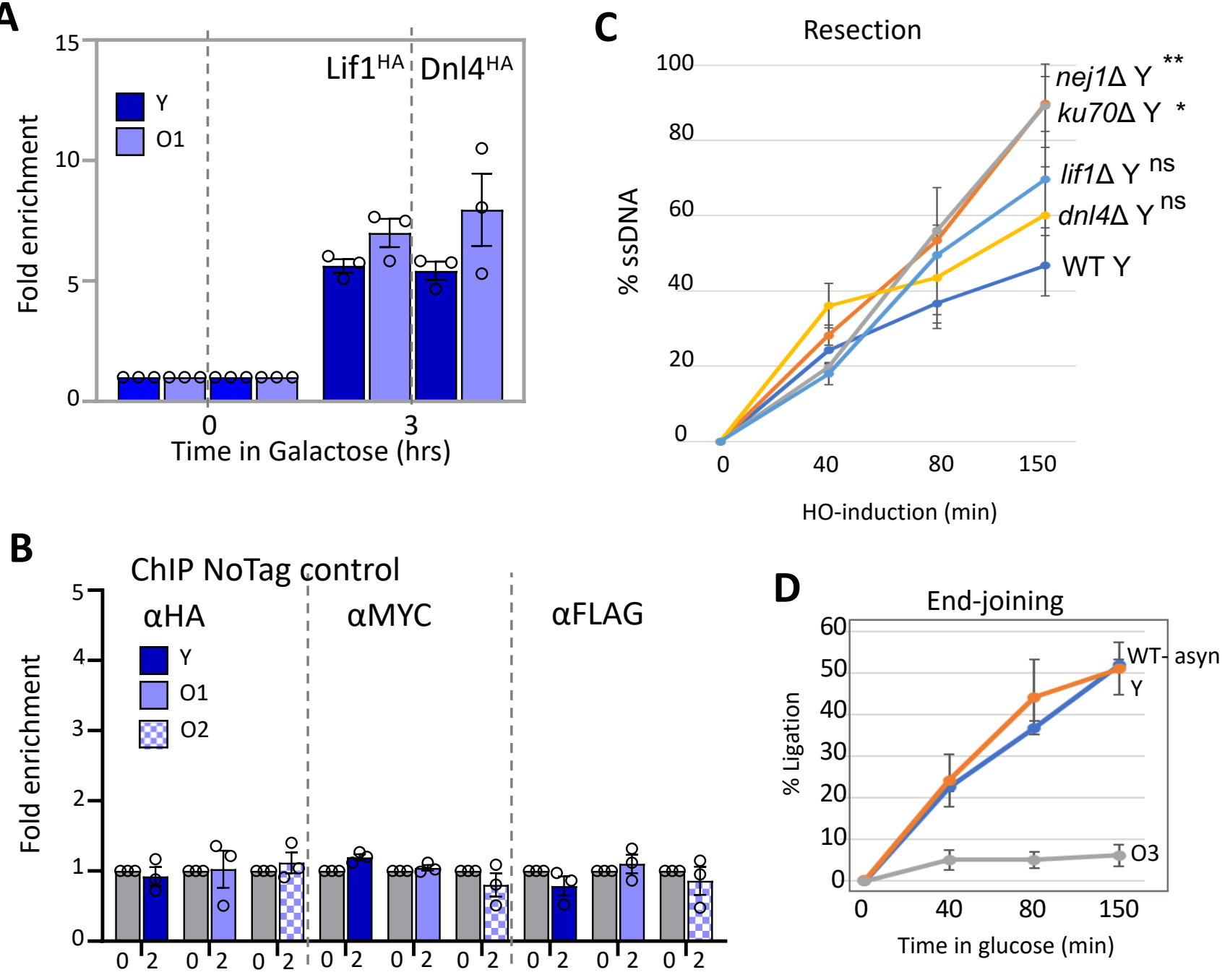

Time in Galactose (hrs)

Figure S3: Supporting information for Figure 3.

(A) Enrichment of Lif1 ${ }^{\mathrm{HA}}$ and Dnl4 ${ }^{\mathrm{HA}}$ (JC-3319 and JC-5672) $0.6 \mathrm{~kb}$ away from the DSB at 0- and 3-hour time point in cells that are young and aged to day 1 . The fold enrichment is normalised to SMC2 locus.

(B) Enrichment of No tag control (JC-727) with $\alpha \mathrm{HA}$, $\alpha \mathrm{MYC}$ and $\alpha \mathrm{FLAG}$ antibody, $0.6 \mathrm{~kb}$ away from the DSB at 0 - and 3 -hour time point in cells that are young, aged to day 1 and day 2 . The fold enrichment is normalised to SMC2 locus.

(C) Resection of DNA $0.15 \mathrm{~kb}$ away from the $\mathrm{HO}$ cut site is measured as the percent of single stranded DNA (ssDNA) at $0,40,80$ and 150 minutes following the induction of the DSB. The strains used were

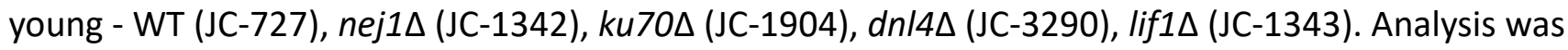
performed in triplicate from at least three biological replicate experiments. Statistical analysis is described in STAR methods.

(D) qPCR-based ligation assay of DNA at HO DSB, as measured by \% Ligation, at 0, 40, 80 and 150 min in cycling cells in glucose post DSB. Strains used were Wild Type - WT (JC-727) without any processing, Young - Y (JC-727) and O3-aged cells that went through the OCE process. 
Table S1: DSB cut efficiency at timepoints used in resection experiments

\begin{tabular}{|c|c|c|c|c|}
\hline \multirow[t]{2}{*}{ Strain } & \multirow[t]{2}{*}{ Genotype } & \multicolumn{3}{|c|}{ HO cutting: } \\
\hline & & $40 \mathrm{~min}$ & $80 \min$ & $150 \mathrm{~min}$ \\
\hline JC-727 -Y & Wild type & 97.66 & 98.76 & 98.69 \\
\hline JC-727 -01 & Wild type & 88.90 & 92.92 & 96.35 \\
\hline JC-727 -O2 & Wild type & 62.54 & 77.16 & 86.48 \\
\hline JC-727 -O3 & Wild type & 45.94 & 71.48 & 77.10 \\
\hline JC-1342 -Y & nej1ム & 98.51 & 98.33 & 98.88 \\
\hline JC-1342 -O1 & nej1 $1 \Delta$ & 97.17 & 98.19 & 98.57 \\
\hline JC-1343 -Y & lif1 $\Delta$ & 94.90 & 95.63 & 97.13 \\
\hline JC-1343 -01 & lif1 $1 \Delta$ & 93.45 & 97.16 & 98.54 \\
\hline JC-1904 -Y & ku70 & 89.22 & 87.03 & 93.88 \\
\hline JC-1904 -01 & ku70 & 91.95 & 91.41 & 93.92 \\
\hline JC-3290 -Y & $d n / 4 \Delta$ & 96.12 & 97.36 & 99.20 \\
\hline JC-3290 -01 & $d n / 4 \Delta$ & 89.05 & 95.08 & 94.00 \\
\hline
\end{tabular}


Table S2: Table of DSB cut efficiency used in ChIP experiments (3 hrs galactose induction).

\begin{tabular}{|c|c|c|c|c|c|}
\hline Strain & Genotype & $\begin{array}{l}\text { DSB cut } \\
\text { (\%) } 3 \mathrm{hrs}\end{array}$ & Strain & Genotype & $\begin{array}{l}\text { DSB cut } \\
\text { (\%) \#hrs }\end{array}$ \\
\hline$J C-727-Y$ & Wild type & 99.75 & JC-3306 -Y & RAD50-6HA & 98.93 \\
\hline JC-727 -01 & Wild type & 99.72 & JC-3306 -01 & RAD50-6HA & 98.61 \\
\hline JC-727 -O2 & Wild type & 82.37 & JC-3306-O2 & RAD50-6HA & 99.13 \\
\hline JC-727 -O3 & Wild type & 73.73 & JC-3319-Y & LIF1-6HA & 99.51 \\
\hline JC-1342 -Y & nej1s & 97.96 & JC-3319-01 & LIF1-6HA & 99.48 \\
\hline JC-1342-01 & nej1s & 99.99 & JC-3802 -Y & MRE11-6HA & 98.97 \\
\hline$J C-1343-Y$ & lif1 $\Delta$ & 99.68 & JC-3802 -01 & MRE11-6HA & 99.32 \\
\hline JC-1343-01 & lif1 $\Delta$ & 99.66 & JC-3802 -02 & MRE11-6HA & 98.85 \\
\hline JC-1510 -Y & NUP133-13MYC & 99.16 & JC-3964 -Y & KU70-FLAG & 98.83 \\
\hline JC-1510 -01 & NUP133-13MYC & 99.05 & JC-3964-01 & KU70-FLAG & 99.46 \\
\hline JC-1510-O2 & NUP133-13MYC & 99.22 & JC-3964-O2 & KU70-FLAG & 99.04 \\
\hline JC-1687 -Y & NEJ1-13MYC & 99.29 & JC-4117 -Y & DNA2-6HA & 99.25 \\
\hline JC-1687 -01 & NEJ1-13MYC & 99.08 & JC-4117 -01 & DNA2-6HA & 99.04 \\
\hline JC-1687 -02 & NEJ1-13MYC & 99.01 & JC-4135 -Y & SGS1-6HA & 99.11 \\
\hline JC-1904 -Y & ku70 & 99.66 & JC-4135 -01 & SGS1-6HA & 99.22 \\
\hline JC-1904 -01 & ku70 & 97.06 & JC-4869 -Y & EXO1-6HA & 99.57 \\
\hline JC-3167 -Y & MPS3-6HA & 99.52 & JC-4869-01 & EX01-6HA & 99.44 \\
\hline JC-3167 -01 & MPS3-6HA & 98.99 & JC-5116 -Y & SAE2-6HA & 98.86 \\
\hline JC-3167 -O2 & MPS3-6HA & 99.12 & JC-5116-O1 & SAE2-6HA & 99.14 \\
\hline JC-3290 -Y & $d n / 4 \Delta$ & 98.56 & JC-5672 -Y & DNL4-6HA & 99.19 \\
\hline JC-3290 -01 & $d n / 4 \Delta$ & 98.24 & JC-5672 -01 & DNL4-6HA & 99.22 \\
\hline
\end{tabular}


Table S3: Yeast strains used in this study.

\begin{tabular}{|c|c|c|}
\hline Strain & Genotype & Reference \\
\hline JC-727 & $\begin{array}{l}\text { MAT } \alpha ; \text { hml::ADE1 hmr::ADE1 ade3::GAL-HO ade1-100 leu2-3, } 112 \text { lys5 } \\
\text { trp1::hisG ura3-52 }\end{array}$ & JKM179, [Lee et al. 1998] \\
\hline JC-1342 & JC-727 with nej1 $\Delta::$ KanMX6 & $\begin{array}{l}\text { MAV015, [Valencia et al. } \\
\text { 2001] }\end{array}$ \\
\hline JC-1343 & JC-727 with lif1 $::$ KanMX6 & Sorenson et al. 2017 \\
\hline JC-1510 & JC-727 with NUP133-13MYC::TRP1 & This study \\
\hline JC-1687 & JC-727 with NEJ1-13MYC::TRP1 & Sorenson et al. 2017 \\
\hline JC-1904 & JC-727 with ku704::KanMX6 & Sorenson et al. 2017 \\
\hline $\mathrm{JC}-3013$ & JC-727 with NUP49-CFP; LaCI-GFP::LEU2; MAT-LaCO::TRP1 & Horigome et al. 2016 \\
\hline $\mathrm{JC}-3167$ & JC-727 with MPS3-6HA::TRP1 & This study \\
\hline JC-3290 & JC-727 with $d n 14 \Delta:: K a n M X 6$ & Sorenson et al. 2017 \\
\hline JC-3306 & JC-727 with RAD50-6HA::TRP1 & Mojumdar er al. 2022b \\
\hline JC-3319 & JC-727 with LIF1-6HA::TRP1 & Sorenson et al. 2017 \\
\hline JC-3802 & JC-727 with MRE11-6HA::TRP1 & Mojumdar er al. 2022b \\
\hline JC-3964 & JC-727 with KU70-FLAG::TRP1 & Mojumdar er al. 2022a \\
\hline JC-4066 & $\begin{array}{l}\text { JC-3585 with ura3::Lacl-mCherry-URA3; leu2::TetR-GFP-LEU2; TAF2- } \\
\text { LacOpFx-TRP1; 4.4kb MAT-TetO-Leu2 }\end{array}$ & Mojumdar er al. 2019 \\
\hline JC-4117 & JC-727 with DNA2-6HA::TRP1 & Mojumdar er al. 2019 \\
\hline JC-4135 & JC-727 with SGS1-6HA::TRP1 & Mojumdar er al. 2022b \\
\hline JC-4869 & JC-727 with EXO1-6HA::TRP1 & Mojumdar er al. 2022b \\
\hline JC-5116 & JC-727 with SAE2-6HA::TRP1 & Mojumdar er al. 2022b \\
\hline JC-5672 & JC-727 with DNL4-6HA::TRP1 & Mojumdar er al. 2022a \\
\hline
\end{tabular}


Table S4: Primers and Probes used in these studies.

\begin{tabular}{|l|l|}
\hline Primer Name & Primer Sequence $\left(\mathbf{5}^{\prime} \mathbf{-} \mathbf{3}^{\prime} \mathbf{)}\right.$ \\
\hline HO2 Forward Primer & TTGCCCACTTCTAAGCTGATTTC \\
\hline HO2 Reverse Primer & GTACTTTTCTACATTGGGAAGCAATAAA \\
\hline HO2 Probe & FAM-ATGATGTCTGGGTTTTGTTTGGGATGCA-TAMRA \\
\hline SMC2 Forward Primer & AATTGGATTTGGCTAAGCGTAATC \\
\hline SMC2 Reverse Primer & CTCCAATGTCCCTCAAAATTTCTT \\
\hline SMC2 Probe & FAM-CGACGCGAATCCATCTTCCCAAATAATT-TAMRA \\
\hline MAT1 Forward Primer & CCTGGTTTTGGTTTTGTAGAGTGG \\
\hline MAT1 Reverse Primer & GAGCAAGACGATGGGGAGTTTC \\
\hline HO6 Forward Primer & AATATGGGACTACTTCGCGCAACA \\
\hline H06 Reverse Primer & CGTCACCACGTACTTCAGCATAA \\
\hline Pre1 Forward Primer & CCCACAAGTCCTCTGATTTACATTCG \\
\hline Pre1 Reverse Primer & ATTCGATTGACAGGTGCTCCCTTTTC \\
\hline
\end{tabular}

